\title{
A Biochemist's View of Long-term Potentiation
}

\author{
Erik D. Roberson, Joey D. English, and J. David Sweatt ${ }^{1}$ \\ Division of Neuroscience \\ Baylor College of Medicine \\ Houston, Texas 77030
}

\begin{abstract}
This review surveys the molecular mechanisms of long-term potentiation (LTP) from the point of view of a biochemist. On the basis of available data, LTP in area CA1 of the hippocampus is divided into three phases-initial, early, and late-and the mechanisms contributing to the induction and expression of each phase are examined. We focus on evidence for the involvement of various second messengers and their effectors as well as the biochemical strategies employed in each phase to convert a transient signal into a lasting change in the neuron. We also consider, from a biochemical perspective, the implications of a multiphase model for LTP.
\end{abstract}

\section{Introduction}

A simple way to think about the concept of memory is as the creation of a persistent change in the brain by a transient stimulus, such as a thought or experience. Long-term potentiation (LTP) is just this sort of phenomenon: A 1-sec stimulus delivered to a group of presynaptic axons causes an increase in the strength of their connections with postsynaptic neurons that lasts for hours, weeks, or months (Fig. 1A). By virtue of this and other properties, LTP has become a memory model studied by researchers in many disciplines, from physiology to molecular biology and from structural biology to behavioral psychology. This review examines the mechanisms of LTP from our perspective as biochemists.

We focus on individual proteins and their in-

\footnotetext{
${ }^{1}$ Corresponding author.
}

teractions. Explanations of LTP in terms of changes in synaptic structure (Edwards 1995) or on the basis of silent synapses becoming functional (Isaac et al. 1995) recently have been proposed. It is worth keeping in mind, though, that even those processes must have some underlying biochemical basis, for any persisting change in a neuron's function must be produced by a persisting change in one or more of its proteins [or, perhaps less likely, in persisting changes to one of its two other macromolecular complexes, DNA and RNA (see Crick 1984)]. Thus, an explanation of LTP in terms of biochemical changes is not mutually exclusive of an explanation based on, for example, structure; in fact, a biochemical explanation is a necessary part of any complete structural explanation.

LTP can be induced in many different synaptic pathways by a variety of induction paradigms, and the biochemical mechanisms of these forms of LTP may differ (e.g., Powell et al. 1994). We focus on the form of LTP whose biochemistry has been studied most extensively: $N$-methyl-D-aspartate (NMDA) receptor-dependent LTP induced by multiple, $1-\mathrm{sec}, 100-\mathrm{Hz}$ tetani at the Schaffer collateral pathway synapses in area CA1 of the hippocampus. We begin by considering briefly the transient biochemical signal for LTP induction, a rise in intracellular calcium. Next, we review current progress in the pursuit of mechanisms that underlie the prolonged effect of this brief signal on synaptic transmission. It appears that LTP is produced by a series of distinguishable mechanisms (Fig. 1B). Thus, our overview of LTP is based on a contemporary model (Fig. 2) that divides LTP into three distinct phases: (1) initial LTP (I-LTP), insensitive to most kinase inhibitors; (2) early LTP (E-LTP), subserved by the second-messenger independent activity of protein kinases, in particular protein kinase $\mathrm{C}$, calcium/calmodulin-dependent protein kinase II, and perhaps others; and (3) late LTP (L-LTP), distinguished from earlier phases based on its dependence on protein synthesis.

LEARNING \& MEMORY 3:1-24 (c) 1996 by Cold Spring Harbor Laboratory Press ISSN1072-0502/96 $\$ 5.00$

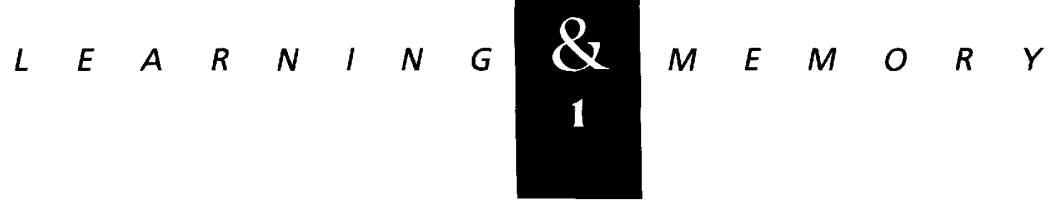




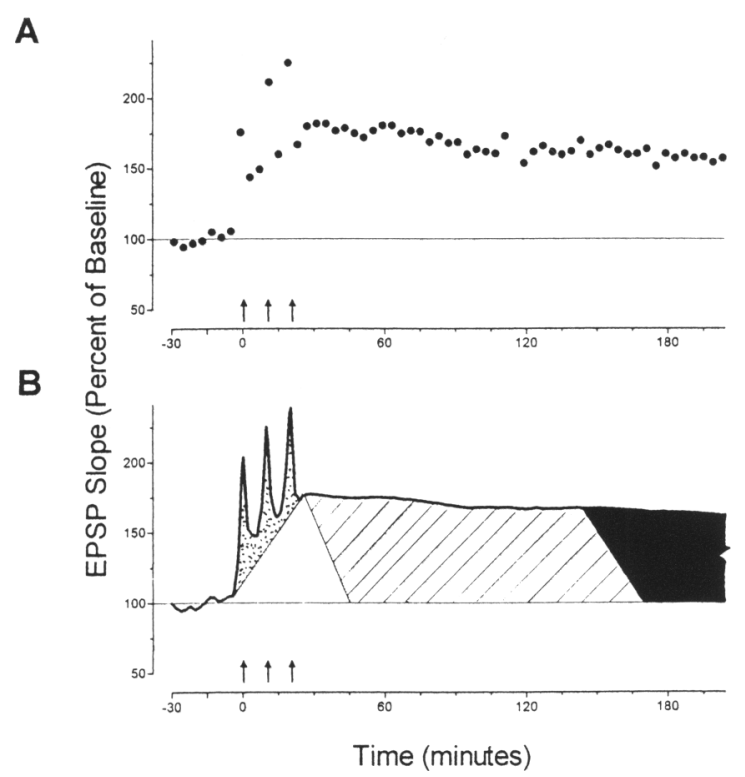

Figure 1: (A) Data from a typical LTP experiment. The slope of the excitatory postsynaptic potential (EPSP), a measure of synaptic strength, is measured over time with an extracellular recording electrode. A steady baseline is observed in response to constant-intensity stimulation of a group of presynaptic fibers. At the times indicated by the arrows, a series of $1-\mathrm{sec}$ stimuli are delivered at 100 $\mathrm{Hz}$. This brief stimulus produces a potentiation of the size of the EPSP which lasts for many hours. This figure illustrates two features of LTP: (1) the persistence of the effect following very brief stimuli, and (2) the stability, i.e., the constant magnitude of potentiation, over presumed transitions between phases of LTP. (B) Schematic diagram of the data from $A$ illustrating the phases of LTP. The potentiation observed in the experiment from $A$ is fit by a LOWESS curve. The various phases of LTP are represented by different shading: PTP, stippled; I-LTP, white; E-LTP, crosshatched; L-LTP, black. Note that succeeding phases overlap, but that during transitions, the observed potentiation remains constant. The duration of each phase is approximate, based on available data (see text).

We distinguish between two types of LTP mechanisms: induction and expression mechanisms. Conceptually, induction mechanisms are defined as the biochemical initial events set into motion to lay the groundwork for a given phase of LTP. These mechanisms are "silent" with respect to synaptic transmission; they do not affect it directly but rather serve to consolidate the subsequent expression mechanism. Induction mechanisms are defined as those processes whose inhibition blocks LTP when the inhibitor is applied only during the inducing stimulus and then washed out. Expression mechanisms, on the other hand, are the processes brought about by the induction mechanisms that support synaptic potentiation directly. They are distinguished from induction mechanisms because inhibition of expression mechanisms after the inducing stimulus causes established LTP to be diminished. Note that when the inhibitor is applied before the inducing stimulus and remains present throughout the experiment, or in a knockout experiment, it is impossible to distinguish between effects on induction and expression. Much more is known about the biochemical cascades that support induction mechanisms. Relatively little is known about expression mechanisms, especially in I-LTP and L-LTP. We will provide a considerable discussion, though, of the expression mechanisms of E-LTP, where there is substantial evidence of a role for protein kinases.

In the model, the increase in intracellular calcium during LTP initiation triggers the induction mechanisms of each of the three phases. After differing delays, each of these induction mechanisms culminates in the expression of enhanced synaptic efficacy and thus provides a component of LTP. Conceptually, then, the potentiation observed during LTP may be divided and attributed to the three expression mechanisms (Fig. 1B).

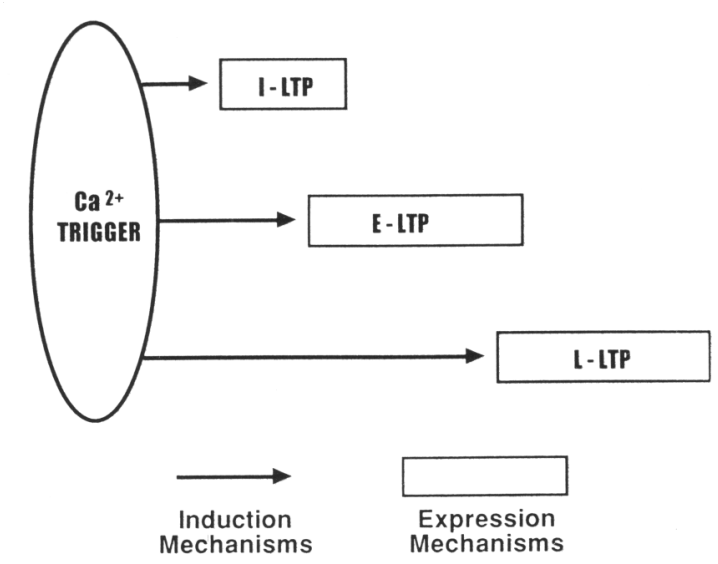

Figure 2: Schematic diagram of the various mechanisms underlying LTP. Calcium influx is the apparent trigger of each phase of LTP, but initiates different mechanisms leading to the various phases. Each phase of LTP comprises an induction mechanism (arrow), which does not contribute directly to potentiation of the EPSP, but serves to consolidate the expression mechanism (box), which does. Note the temporal overlap between multiple induction and expression mechanisms; for clarity, these mechanisms are represented as independent, but interactions between mechanisms are likely.

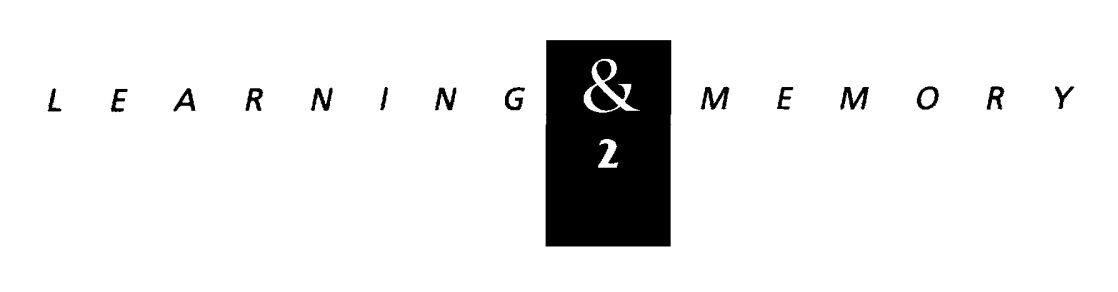


For clarity, the phases are represented as completely independent in Figure 2 . The extent to which this is true and the means by which the three phases may interrelate is discussed below.

\section{The Transient Signal}

We begin by considering the nature of the transient signal. From a biochemical point of view, a brief rise in postsynaptic intracellular calcium above some threshold level serves as the trigger for LTP. There is a variety of evidence to support this, including the fact that calcium chelators injected postsynaptically can prevent the induction of LTP (Lynch et al. 1983), and that photolytic release of calcium from cage compounds in the postsynaptic cell can trigger a long-lasting potentiation like LTP (Malenka et al. 1988). We focus on where and when calcium levels increase and on what constraints this signal might place on mechanisms for LTP, with the goal of understanding the mechanisms induced by the calcium trigger.

\section{CALCIUM IMAGING}

Imaging studies with calcium-sensitive dyes have provided a great deal of information concerning the spatial and temporal characteristics of calcium signaling in hippocampal neurons. Such techniques allow for the selective loading of either the pre- or postsynaptic cell and thus the study of the location and duration of calcium signals on either side of the synapse.

Several investigators have used these techniques to examine postsynaptic calcium levels at Schaffer collateral synapses and have shown that synaptic transmission leads to a rise in calcium levels in both the dendrites and somas of pyramidal neurons (Miyakawa et al. 1992; Regehr and Tank 1992).

Calcium imaging studies indicate that the postsynaptic calcium transient induced by highfrequency stimulation peaks during the tetanus and returns to resting levels within seconds (Regehr and Tank 1992; Perkel et al. 1993). The fact that a very brief rise in postsynaptic calcium levels is sufficient for LTP induction is consistent with observations that calcium chelation following high-frequency stimulation by $3 \mathrm{sec}$ does not block LTP, although chelation 1 sec post-tetanus does (Malenka et al. 1992). This is indeed an ex- tremely brief period of time during which calcium must set in motion numerous, long-lasting biochemical changes at the synapse.

\section{CALCIUM SOURCES}

There are two potential sources of the calcium trigger for LTP: extracellular calcium influx and calcium release from intracellular stores. Influx of extracellular calcium is mediated by at least two classes of transmembrane ion channels: the NMDA subtype of glutamate receptor and voltagegated calcium channels (VGCCs).

NMDA receptors contribute little to normal synaptic transmission because of a voltage-dependent magnesium block; the depolarization that occurs during high-frequency stimulation relieves this block, and, with glutamate present at the active synapse, calcium influx via activated NMDA receptors occurs. NMDA receptor activation is required for LTP induction, as LTP is blocked by a variety of NMDA receptor antagonists acting at various sites on the receptor. These include the competitive antagonist 2-amino-5-phosphonopentanoic acid (APV) (Collingridge et al. 1983; Harris et al. 1984), the open-channel blocker (5R, 105)5-methyl-10, 11-dihydro-5H-dibenzo[a,d]cyclohepten-5, 10-imine hydrogen malente (MK-801) (Coan et al. 1987), and an antagonist of the glycine modulatory site, 7-chlorokynurenate (Bashir et al. 1990 ). Imaging studies suggest that near activated synapses, the dendritic calcium transient is attenuated by APV (Regehr and Tank 1992). As the authors point out, however, this result does not mean that all synaptic calcium permeates through NMDA receptors; APV, by blocking NMDA receptor-mediated depolarization, may also attenuate calcium flux through VGCCs.

In fact, most of the calcium influx that follows an LTP-inducing tetanus, especially in the proximal dendrites and soma, depends on VGCCs that are activated by sodium spikes spreading through the cell (Miyakawa et al. 1992). In synaptic zones, calcium flux through NMDA receptors may be amplified by VGCCs activated by the excitatory postsynaptic potential (EPSP). Although experiments with antagonists of L-type VGCC suggest that their activation is not required for LTP induction (Taube and Schwartzkroin 1986), it is difficult to rule out a contribution from other subtypes of VGCCs.




In addition to influx of extracellular calcium, release of calcium from intracellular stores appears to be involved in the initiation of LTP. Two regulatory mechanisms for such release have been described: release triggered by inositol 1,4,5triphosphate $\left(\mathrm{IP}_{3}\right)$, a second messenger generated downstream of many metabotropic receptors $\left(\mathrm{IP}_{3}\right.$ induced release), and release stimulated by influx of extracellular calcium (calcium-induced calcium release). Thapsigargin, which depletes intracellular calcium stores and thus interferes with both mechanisms, and dantrolene, which antagonizes the ryanodine receptor and inhibits calcium-induced calcium release, both block LTP induction (Obenaus et al. 1989; Harvey and Collingridge 1992).

Several points regarding the LTP-triggering calcium transient are important. First, there is good evidence that calcium is involved in triggering LTP. Second, an LTP-inducing stimulus causes transient increases in calcium concentration throughout the postsynaptic cell, including both the dendritic shaft and soma. Thus, we may expect that biochemical cascades residing in each of these compartments may be initiated during LTP.

Third, although LTP in area CA1 is typically classified as being NMDA receptor-dependent, it is likely that the calcium trigger for LTP induction is provided by not only NMDA receptors, but also VGCCs and release from intracellular stores. Thus, local calcium concentrations can be expected to be highest not only at the post-synaptic density where NMDA receptors are located, but also along the membrane wherever VGCCs are activated and near the spine apparatus where release from stores takes place.

Finally, calcium returns to resting levels in the postsynaptic cell within seconds to a few minutes, long before the end of even the initial phase of LTP. That is, the signal itself is not persistent; the continued expression of potentiation must be mediated by some downstream process.

\section{The Persistent Effect}

An LTP-inducing tetanic stimulus elicits an immediate enhancement of synaptic transmission. The earliest potentiation, known as post-tetanic potentiation (PTP), does not outlast the transient calcium signal. The time course of PTP, which has been demonstrated at many central nervous system (CNS) synapses, including synapses that do not undergo LTP, appears to parallel the decay of presynaptic calcium levels (Swandulla et al. 1991; Kamiya and Zucker 1994). In fact, the remaining tetanus-induced elevation of calcium levels is thought to augment normal calcium-dependent neurotransmitter release by increasing the release probability. When LTP is blocked with either the NMDA receptor antagonist APV or postsynaptic loading of calcium chelators, PTP remains the sole enhancement of transmission (Collingridge et al. 1983; Lynch et al. 1983; Malenka et al. 1988). Thus, we do not consider PTP to be a part of LTP for the purposes of this review.

The hallmark of ITP is that the enhancement of synaptic strength survives the decay of the signal that initiates it. Thus, once the calcium transient (and PTP) decays, continued potentiation constitutes LTP. The mechanisms that support this potentiation, that is, the means by which the transient calcium signal produces a sustained effect, are the focus of these sections. We consider three phases of LTP, each of which constitutes an example of a persistent effect on synaptic strength outlasting the transient calcium signal.

\section{INITLAL LTP}

The initial phase of LTP (I-LTP) was first revealed in studies on the effects of the general protein kinase inhibitor $\mathrm{H}-7$ on LTP. In the presence of $\mathrm{H}-7$, a standard LTP-inducing tetanus yields only a decremental potentiation lasting on the order of 30 min (Malinow et al. 1988). Since this observation, a battery of nonspecific protein kinase inhibitors have been used in the study of LTP, and these experiments suggest the existence of a decremental potentiation lasting $25-45 \mathrm{~min}$ that is largely insensitive to broad-spectrum protein kinase inhibitors. Often referred to as short-term potentiation (STP), we call it I-LTP to emphasize that, like later phases of LTP, the potentiation outlasts the transient calcium signal and thus must have an additional expression mechanism.

The specific mechanism of I-LTP has been difficult to determine. I-LTP depends on the same calcium signal as later phases, being blocked by either APV or postsynaptic injection of calcium chelators (Collingridge et al. 1983; Lynch et al. 1983). However, the biochemical mechanisms that underlie I-LTP appear to be quite distinct from the mechanisms of E-LTP and L-LTP, because

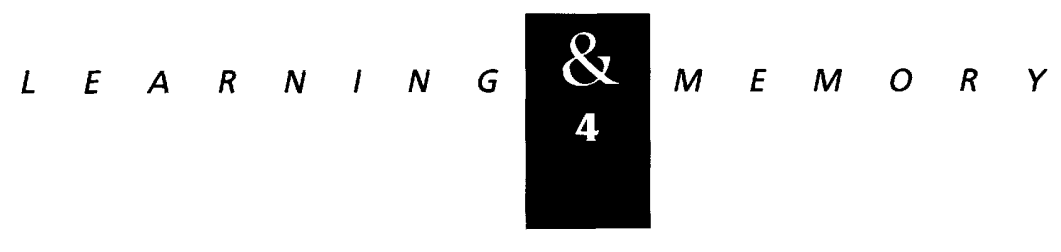


few other compounds known to block later stages of LTP affect it. One possible exception is the nitric oxide synthase (NOS) inhibitor nitroarginine, which when reported to have any effect upon LTP seems to block all phases, including I-LTP; only PTP remains (Böhme et al. 1991; O'Dell et al. 1991a; Schuman and Madison 1991; Haley et al. 1993; Williams et al. 1993). The inhibition of potential components of the NOS signaling pathway-guanylyl cyclase, ADP-ribosyltransferase, and cGMP-dependent kinase-also appears to block I-LTP (Schuman et al. 1994; Zhuo et al. 1994). While the role of the NOS pathway remains controversial in LTP (see below), it is nonetheless interesting that this pathway might be involved in this earliest, largely kinase-independent phase of LTP.

\section{EARLY LTP}

Like the other phases of LTP, the induction of E-LTP begins in response to the initial, triggering elevations of calcium. The expression of E-LTP begins soon after tetanus and overlaps in time with I-LTP; it ends several hours later when the proteinsynthesis-dependent late phase takes over. We begin by considering the roles of various protein kinases, both serine/threonine kinases and tyrosine kinases, and then examine involvement of a series of diffusible compounds that putatively function as intercellular messengers.

E-LTP is the only phase for which much is known about the expression mechanisms, the processes brought about to increase synaptic strength. To achieve this goal in E-LTP, the neuron generates "autonomously active" protein kinases. When activated by a second messenger, many protein kinases can generate a novel form that is subsequently active independent of the continued presence of the second messenger. In the context of an LTP mechanism, second messengers inducing a state of autonomous kinase activation can explain how transient activation of a cell-surface receptor and a corresponding short-lived increase in a second messenger can lead to a long-term change in effector enzyme activity (Lisman 1985; Schwartz 1993). Both protein kinase C (PKC) and calcium/calmodulin-dependent kinase II (CaMKII) can be rendered autonomously active by calcium, and numerous studies have implicated their involvement in E-LTP. For each of these two kinases we describe the mechanisms operating to generate the autonomously active form of the kinase, the data supporting its necessity and sufficiency for LTP, and known substrates likely to contribute to mediating its effects. It should be noted that to date few studies have investigated whether either of these kinases is necessary for late LTP; all of the studies referred to below used a time course for LTP in the range of $<1-2 \mathrm{hr}$.

In addition to evidence for autonomous activation of PKC and CaMKII in E-LTP expression, there is strong evidence of a role for these kinases in E-LTP induction. During E-LTP induction the autonomous activation of PKC and CaMKII must occur. Interestingly, autophosphorylation of each kinase is a possible mechanism for its autonomous activation. Thus, kinase activation may underlie both an induction mechanism (via second messenger-dependent activation) and an expression mechanism (via autonomous activation).

PKC

Several lines of evidence indicate a role for PKC activation in both the induction and expression of E-LTP in the hippocampus. A large body of data supports the idea that PKC may underlie expression of E-LTP: PKC inhibitors can reverse E-LTP; both presynaptic and postsynaptic PKC activation lead to increased synaptic efficacy; autonomous activation of PKC occurs during E-LTP; PKC substrates have their phosphorylation increased in LTP; and several mechanisms for the persistent activation of PKC have been described. Similarly, data indicate a necessity for PKC activity in the induction of E-LTP. In this section we survey the data supporting a role for PKC in the induction and expression of E-LTP.

PKC AND E-LTP INDUCTION A variety of cell-permeant protein kinase inhibitors have been used to implicate PKC in E-LTP induction. Several inhibitors known to block PKC activity in vitro have been shown to block E-LTP induction when applied during the initiation of LTP; as mentioned above, I-LTP is unaffected by these inhibitors. These include mellitin (Lovinger et al. 1987), polymyxin B (Lovinger et al. 1987; Colley et al. 1990; Wang and Feng 1992), H-7 (Malinow et al. 1988; Colley et al. 1990; Wang and Feng 1992), k-252a (Matthies et al. 1991), k-252b (Reymann et al.

$$
\ldots \ldots, \ldots, \ldots
$$


1988a; Reymann et al. 1990; Matthies et al. 1991), sphingosine (Malinow et al. 1988), and staurosporine (Denny et al. 1990b; Matthies et al. 1991; Muller et al. 1992). However, the interpretation of these experiments is limited because all of these inhibitors block other kinases in addition to PKC (Ruegg and Burgess 1989; Hidaka and Kobayashi 1992) and may have nonspecific effects on other enzymes or ion channels (Amador and Dani 1991).

Additional evidence for PKC involvement has come from studies using selective inhibitor peptides. Postsynaptic injection of the PKC inhibitor peptides $\mathrm{PKC}_{19-31}$ or $\mathrm{PKC}_{19-36}$ blocks induction of LTP (Malinow et al. 1989; Wang and Feng 1992). In these experiments modified peptides that are much less potent inhibitors of PKC do not block LTP (Malinow et al. 1989). In a transgenic version of the PKC inhibition experiment, mutant mice lacking the $\gamma$ isoform of PKC exhibit deficits in LTP induction, though these deficits can be overcome by certain conditioning stimuli (Abeliovich et al. 1993). The ability to induce LTP under some conditions in the PKC $\gamma$ mutant mouse, however, may be due to contributions from other isoforms of this kinase.

It should be emphasized that in almost all of the studies described above using cell-permeant inhibitors, inhibitor peptides, or knockout mice, PKC inhibition was begun before LTP-inducing stimulation and continued throughout the experiment. Therefore, although we have included these studies in the category of inhibition of LTP induction, it is difficult to distinguish whether the effects reported are on E-LTP induction or on the expression of E-LTP. Several studies, however, notably those of Malinow et al. (1988), Huber et al. (1995), and Wang and Feng (1992), distinguish between effects on E-LTP induction versus E-LTP expression. These studies are consistent with the involvement of PKC in both E-LTP induction and expression.

Finally, both Klann et al. (1993) and Sacktor et al. (1993) have shown activation of PKC within minutes of tetanic stimulation, measured using direct in vitro methods (see below). Overall, data generated using PKC inhibitors, transgenic mice, and direct assays of PKC activity are consistent with a role for PKC in the induction of E-LTP. However, it should be pointed out that a transient increase in PKC activity is not sufficient to induce lasting LTP. Activation of PKC with phorbol esters does not result in long-lasting potentiation; synap- tic responses return to baseline following washout of the drug (Muller et al. 1988).

PKC AND E-LTP EXPRESSION Several different approaches have been used to study the involvement of PKC in the expression of E-LTP. Inhibitors have been used to show that PKC activity is necessary for E-LTP, and activators have demonstrated that increased PKC activity can lead to synaptic potentiation. Finally, PKC substrate phosphorylation has been studied, and PKC activity directly assayed, to demonstrate that autonomous activation of PKC does occur during E-LTP expression.

Kinase Inbibitor Studies Inhibitor studies have provided evidence that continued activity of protein kinases is in fact required for the expression of E-LTP (Lovinger et al. 1987; Colley et al. 1990; see also Huber et al. 1995). The kinase inhibitor $\mathrm{H}-7$, which blocks the catalytic activity of PKC by competitive inhibition with ATP (Hidaka et al. 1984; Hidaka and Kobayashi 1992), blocks reversibly the expression of E-LTP (Malinow et al. 1988). Staurosporine, another ATP-competitive kinase inhibitor, also has been shown to decrease established E-LTP (Matthies et al. 1991), although a contradictory report has been published (Denny et al. 1990b). On the other hand, the PKC inhibitor sphingosine, which competes with secondmessenger activators of PKC but does not attenuate established PKC activity (Hannun et al. 1986; Hidaka and Kobayashi 1992), blocks E-LTP induction but not its expression (Malinow et al. 1988). These reports are consistent with the hypothesis that E-LTP expression depends on continued, autonomous kinase activity.

Postsynaptic injection of $\mathrm{PKC}_{19-31}$ plus the PKC inhibitor polymyxin B either $75 \mathrm{~min}$ or $3 \mathrm{hr}$ following LTP induction also blocks LTP expression (Wang and Feng 1992), suggesting that the continued activity of postsynaptic $\mathrm{PKC}$ is required for E-LTP expression, although another report implicates presynaptic PKC activity (Malinow et al. 1989).

Kinase Activator Studies The tumor-promoting phorbol esters are potent activators of PKC (Castagna et al. 1982). Application of active phorbol esters causes a robust, transient increase in synaptic transmission in the hippocampus (Malenka et al. 1986; Malenka et al. 1987; Hvalby et al. 1988; Kamiya et al. 1988; Muller et al. 1988,1990; Reymann et al. 1988b). The increase in synaptic transmission caused by phorbol-estermediated PKC activation appears to be due to a

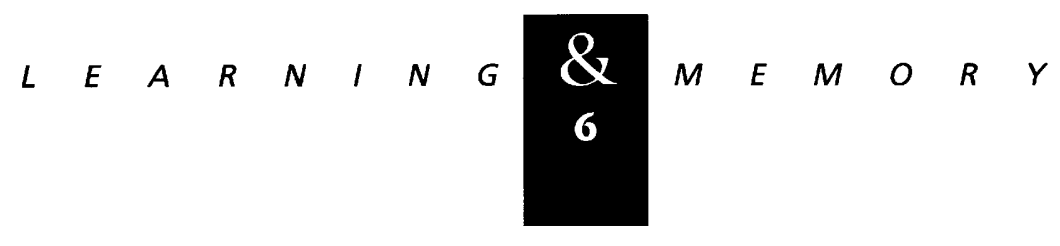


presynaptic effect (Malenka et al. 1986, 1987). In addition, injection of active PKC into postsynaptic neurons also results in synaptic potentiation ( $\mathrm{Hu}$ et al. 1987). These experiments indicate that increased PKC activity is sufficient to cause synaptic potentiation.

Kinase Substrate Studies A role for changes in protein phosphorylation in LTP was first demonstrated in studies of unidentified protein kinase substrates (Lynch et al. 1979). In these early studies, LTP was found to be associated with increased protein phosphorylation, implicating altered kinase activity in LTP, but the identity of the potentiating kinases and substrates was not known at that time. Once evidence began to accumulate that PKC was likely to play a role in LTP, the search began for likely substrates for the activated PKC. In some of the earliest studies, the phosphorylation state of the PKC substrate GAP43 (also known as F1 or B50) was found to be altered in post hoc biochemical assays in association with LTP (Akers and Routtenberg 1985; Lovinger et al. 1985; Akers et al. 1986; Nelson et al. 1989), and direct labeling of hippocampal slices in situ with radioactive inorganic phosphate has confirmed that the phosphorylation of GAP 43 is increased for at least $1 \mathrm{hr}$ following LTP induction (Gianotti et al. 1992). Also, increased GAP43 phosphorylation associated with LTP has been demonstrated using antibodies that recognize GAP43 phosphorylated at the PKC phosphorylation site (Leahy et al. 1993). GAP43 is a particularly interesting PKC substrate: It is nervous-tissue specific (Aloyo et al. 1982 ); it is located predominantly in the presynaptic terminal (van Hooff et al. 1986; van Lookeren Campagne et al. 1989); and its degree of phosphorylation is positively correlated with neurotransmitter release (Dekker et al. 1989a,b).

An LTP-associated increase in the phosphorylation of another PKC substrate has also been demonstrated. A 17-kD PKC substrate that resembles neurogranin (also known as RC3) (Baudier et al. 1989; Represa et al. 1990; Watson et al. 1990; Baudier et al. 1991) shows increased phosphorylation in association with LTP (Klann et al. 1992; Chen et al. 1993; Fedorov et al. 1995; Ramakers et al. 1995). Interestingly, in contrast to GAP43, neurogranin is a predominantly postsynaptic PKC substrate (Baudier et al. 1991).

Both GAP43 and neurogranin are calmodulinbinding proteins. Both bind calmodulin in the absence of calcium and release calmodulin when calcium levels increase. Phosphorylation of GAP43 or neurogranin by PKC causes the calmodulin binding affinity to decrease dramatically. Therefore, one effect of PKC activation in LTP is likely to be increased intracellular concentrations of calmodulin. This has interesting implications concerning potential cross talk between PKC and CaMKII in LTP (Ocorr and Schulman 1991; Wang and Feng 1992; Wang and Kelly 1995).

Kinase Assay Studies Several recent studies have measured directly the activity of protein kinases in post hoc assays following the induction of LTP. Klann et al. showed that a lasting increase in autonomous PKC activity is associated with E-LTP (Klann et al. 1991). Subsequent studies suggested that one mechanism of the persistent PKC activation during LTP expression involves increased phosphorylation of PKC (Klann et al. 1993; Schwartz 1993).

A role for PKC activity in E-LTP expression has also been implicated in studies using antibodies that recognize various $\mathrm{PKC}$ isoforms. Sacktor et al. (1993) found that an increase in an active, catalytic fragment of the PKC $\zeta$ isoform (PKM $\zeta$ ) is associated with LTP $30 \mathrm{~min}$ after the initiation of LTP. This increase in the amount of PKM $\zeta$ is interpreted as an increase in autonomous PKC activity because this fragment can autophosphorylate in the absence of PKC activators (Sacktor et al. 1993), and proteolysis is a well-documented mechanism for PKC activation (see below).

Taken together, these lines of evidence indicate a role for PKC in the expression of E-LTP: PKC inhibitors can reverse E-LTP; either presynaptic or postsynaptic PKC activation leads to increased synaptic efficacy; phosphorylation of PKC substrates increases in LTP; and autonomously active PKC increases during E-LTP expression.

MECHANISMS OF AUTONOMOUS PKC ACTIVATION IN LTP We conclude this section by focusing on the mechanisms that operate during LTP to generate the autonomously active PKC. This is how the transient signal is converted into a persistent effect on PKC, and is an area in which some molecular details are known. The various $\mathrm{PKC}$ isozymes have in common activation by phospholipids. PKC can be activated by numerous second messengers such as diacylglycerol, arachidonic acid (along with other unsaturated free fatty acids), and calcium, all of which are typically short-lived intracellular messengers (Nishizuka 1992). Thus, PKC activation in response to typical second-messenger activation is transient. However, as we have mentioned, several means exist

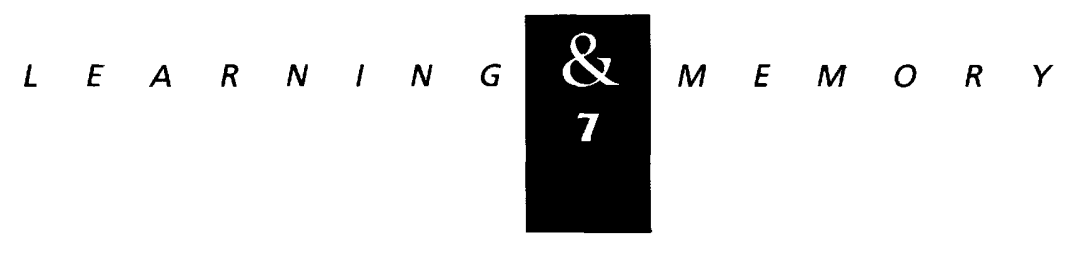


whereby PKC can be activated in an autonomous manner, independent of the continued presence of a second messenger. Many of these mechanisms may be involved in the autonomous activation of PKC during E-LTP.

Proteolysis The most well-characterized mechanism for generating an increase in autonomous PKC activity is proteolytic activation (Inoue et al. 1977; Kishimoto et al. 1983, 1989; Huang and Huang 1986). Proteolytic activation of PKC occurs when the regulatory domain is removed, leaving the 45 - to $50-\mathrm{kD}$ catalytic domain (known as PKM) that is active in the absence of secondmessenger activators (Inoue et al. 1977; Kishimoto et al. 1983, 1989; Huang and Huang 1986). Proteolysis by calcium-dependent neutral proteases or trypsin can activate PKC (Inoue et al. 1977; Kishimoto et al. 1983, 1989; Huang and Huang 1986). The calcium-dependent proteases calpain I (active at micromolar calcium concentrations) and II (active at millimolar calcium concentrations) provide a regulatable means of persistent PKC activation. Interestingly, inhibitors of calpain block the induction of LTP (del Cerro et al. 1990b; Denny et al. 1990a). An increase in a proteolytic fragment of PKC has been observed in LTP in the hippocampus (Sacktor et al. 1993; Powell et al. 1994). Specifically, Sacktor et al. (1993) demonstrated proteolytic activation of the $\mathrm{PKC} \zeta$ isoform in E-LTP.

Autophosphorylation Autophosphorylation of PKC in the presence of calcium and phospholipid is known to occur (Huang et al. 1986; Mochly-Rosen and Koshland 1987; Flint et al. 1990; Hannun and Bell 1990). PKC autophosphorylation is likely via an intramolecular reaction (Mochly-Rosen and Koshland 1987). The sites of autophosphorylation are found in three separate regions of PKC's primary sequence, including a serine and a threonine near the amino terminus, two threonines in the V3 "hinge" region, and two threonines near the carboxyl terminus (determined for PKC $\beta I$ ) (Flint et al. 1990). Autophosphorylation of PKC lowers its $K_{m}$ for calcium, analogous to the effects of diacylglycerol (DAG), and a subtle increase in activity occurs even in the absence of calcium (Huang et al. 1986). Autophosphorylated PKC also has a higher affinity for phorbol ester binding (Huang et al. 1986). At the present time, it remains to be determined directly whether autophosphorylation of PKC can lead to its autonomous activation. Klann et al. (1993) observed that E-LTP expression is associated with increased phosphorylation of PKC. These authors hypothesized that PKC autophosphorylation contributes to the autonomous PKC activity observed during E-LTP expression. Finally, although autophosphorylation of $\mathrm{PKC}$ is a likely mechanism for its increased phosphorylation in LTP, the data of Klann et al. (1993) are consistent with PKC being activated by transphosphorylation by another kinase.

Membrane Insertion Another interesting mechanism of persistent PKC activation in vitro is membrane insertion. In the presence of phospholipid vesicles, calcium induces PKC binding to membranes and causes a subpopulation of PKC to become inserted into the membrane (Bazzi and Nelsestuen 1988). The "membrane-inserted" PKC is active in the absence of calcium, DAG, phorbol esters, and additional phospholipids and is not readily dissociated from the membrane by washing with ethylene glycol-bis-( $\beta$-amino-ethyl ether) $\mathbf{N}, \mathbf{N}, \mathbf{N}^{\prime}, \mathbf{N}^{\prime}$-tetracetic acid (EGTA) (Bazzi and Nelsestuen 1988). Routtenberg and coworkers observed an increased membrane association of PKC in LTP, consistent with the possibility of persistent activation of PKC in LTP through membrane insertion (Akers et al. 1986).

To summarize, at a minimum the induction mechanism for E-LTP is likely to include autophosphorylation (or transphosphorylation) of PKC, a proteolytic activation of the PKC $\zeta$ isoform, and perhaps membrane insertion of PKC. It will be interesting to determine whether additional mechanisms for generating autonomously active PKC are also involved in LTP.

\section{CAMKII}

In 1985, John Lisman published a landmark paper providing insight into the biochemical mechanisms likely to contribute to memory formation. Lisman described how a kinase that upon autophosphorylation is autonomously activated can become permanently active and thereby serve as a memory storage device. Francis Crick in 1984 published a similar, theoretical insight. Subsequently, it was discovered that CaMKII has many (perhaps all) of the properties necessary for permanent activation (Lisman and Goldring 1988). These theoretical considerations plus substantial experimental evidence from a variety of investigators has led to the formulation of the CaMKII hypothesis of memory formation. The data implicat-




ing a role for CaMKII in LTP and memory formation have been discussed recently in an informative review by Lisman (1994), so we provide only a brief overview.

MECHANISM OF PERSISTENT ACTIVATION OF CaMKII CaMKII is a multi-subunit enzyme. Each of the 10-12 subunits in the holoenzyme has a catalytic domain and an autophosphorylation domain. CaMKII, upon activation by calcium and calmodulin, can autophosphorylate by an intersubunit, intraholoenzyme reaction. The autophosphorylated enzyme is autonomously active, that is, it is active independent of the continued presence of calcium and calmodulin. This mechanism sets up a self-perpetuating CaMKII activation that may be independent of subunit turnover and can theoretically last the lifetime of the neuron. It can be hypothesized that this mechanism in and of itself may be sufficient for LTP, independent of any subsequent changes in gene expression (Lisman 1985 , 1994).

EFFECTS OF CAMKII INHIBITION ON E-LTP A number of studies have indicated a necessary role for CaMKII in E-LTP. A cell-permeant inhibitor of CaMKII, KN-62, blocks E-LTP induction (Ito et al. 1991). Also, inhibitors of the calcium-binding second messenger calmodulin such as trifluoperazine (Finn et al. 1980) and calmidazolium (Malenka et al. 1989) can block E-LTP. While these agents can inhibit other processes (Greenberg et al. 1987; Hidaka and Kobayashi 1992), they generally implicate CaMKII or calmodulin-dependent processes in E-LTP.

Additional evidence for involvement of CaMKII in E-LTP has come from studies using inhibitor peptides. Postsynaptic injection of the CaMKII inhibitor peptide CaMKII ${ }_{273-302}$ blocks E-LTP (Malinow et al. 1989). In these experiments, modified peptides, which are much less potent inhibitors of CaMKII, do not block E-LTP (Malinow et al. 1989). Two calmodulin binding peptides, CBP and $\mathrm{CBP}_{-3}$, also block E-LTP when injected postsynaptically (Malenka et al. 1989). However, recent evidence has suggested that CaMKII inhibitor peptides may in fact be acting through inhibition of PKC (Hvalby et al. 1994).

The use of genetically altered mice lacking the $\alpha$ subunit of CaMKII has provided another means to study kinase involvement in E-LTP that is analogous to kinase inhibition. Mice lacking the $\alpha$ CaMKII are deficient in E-LTP, though it is not eliminated in all cases (Silva et al. 1992). The ability to induce LTP under some conditions in the $\alpha$ CaMKII mutant mouse, however, could be due to contributions from a CaMKII composed of $\beta$ subunits, which are still present in the mutant mouse. Although these mice exhibited apparently normal synaptic transmission, the possible effects of genetic alterations on neuronal development confounds the interpretation of these experiments. In fact, it has been reported recently that the $\alpha$ CaMKII knockout mice are epileptic (Butler et al. 1995), which calls into question the basis for the deficit in LTP that these animals exhibit.

Overall, the CaMKII inhibitor data support a necessity for CaMKII in E-LTP. In most of these studies, however, the inhibitors were present throughout the experiment, so it is difficult to discriminate between effects on induction and expression. However, the study of Ito et al. (1991) demonstrated that E-LTP is blocked by $\mathrm{KN}-62$ even when the inhibitor is washed out immediately after the inducing stimulus, indicating an effect on E-LTP induction. In fact, KN-62 had no effect on E-LTP expression in this study. A contrasting report, though, suggests that peptide inhibitors of CaMKII do block E-LTP expression when injected postsynaptically (Feng and Wang 1992). Thus, although it seems clear that CaMKII plays some role in E-LTP, it remains to be seen whether its role is primarily in induction, or also in expression of the potentiation.

KINASE ASSAY STUDIES Direct assays of CaMKII activity have implicated a role for its autonomous activation in L'TP expression (Fukunaga et al. 1993). An increase in both autonomous and second-messenger-dependent CaMKII activity occurs 5 min following LTP induction and lasts for at least $60 \mathrm{~min}$ (Fukunaga et al. 1993). These results are consistent with a role for CaMKII in the expression of E-LTP. In addition, Pettit et al. (1994) have shown recently that activation of CaMKII is sufficient to increase synaptic efficacy. These workers transfected active CaMKII into hippocampal neurons and showed an augmentation of synaptic transmission and an occlusion of the subsequent induction of LTP. This finding must be interpreted with caution, however, as Mayford et al. (1995) have reported contradictory findings in a transgenic animal expressing autonomously active CaMKII.

KINASE SUBSTRATE STUDIES In an elegant series of experiments, Soderling's group has demonstrated that CaMKII can phosphorylate and activate glutamate receptors, a mechanism that clearly could contribute to the expression of LTP




(McGlade-McCulloh et al. 1993). This work has demonstrated that the GluR1 glutamate receptor subunit can be phosphorylated in vitro at $\operatorname{Ser}_{627}$ by CaMKII, and that phosphorylation at this residue in an expressed glutamate receptor can cause an enhancement of the receptor's conductance.

While some contradictory reports have appeared, the available data support a role for CaMKII in the induction of LTP and a contribution of autonomously active CaMKII in the expression of E-LTP. As mentioned above, little data are available concerning the role of CaMKII in late LTP. This would be interesting to investigate given the possibility of permanent activation of CaMKII via autophosphorylation and autonomous activation.

PKA

The cyclic AMP-dependent protein kinase (PKA) is considered to play a role in the induction of L-LTP, as described below. However, evidence suggests some role for PKA in E-LTP induction as well. Bath application of PKA inhibitors during the initiation of LTP reduces the magnitude of E-LTP (Huang and Kandel 1994). More recently, it has been shown that when a PKA inhibitor is applied intracellularly via a whole cell patch pipette, E-LTP induction is prevented (Blitzer et al. 1995). PKA inhibitors do not have any effect on E-LTP expression, as the inhibitors do not reverse already established LTP (Huang and Kandel 1994).

The specific role played by PKA in E-LTP is unknown, but it is hypothesized that PKA causes inhibition of phosphatase activity, which would promote the action of PKC, CaMKII, and other kinases. In an elegant experiment, Blitzer et al. (1995) demonstrated that inclusion of a phosphatase inhibitor with the PKA inhibitor in the recording pipette rescues $L T P$, suggesting that the relevant function of PKA during LTP is to block phosphatase activity. PKA is capable of down-regulating phosphatases by phosphorylating inhibitor1 , a phosphatase inhibitor active only when phosphorylated. Blitzer et al. (1995) suggest that a cell's normal phosphatase activity may prevent LTP, and that PKA allows LTP to be induced by opening this "gate" through phosphorylation of inhibitor-1. It would be interesting to determine whether inhibitor- 1 is in fact a PKA substrate during LTP.
TYROSINE KINASES

Protein tyrosine kinases (PTKs) generally have been considered in the context of regulating cellular proliferation and differentiation in mitotic cells (Cantley et al. 1991). It is therefore interesting to note that many PTKs are expressed at high levels in post-mitotic neuronal cells and that PTK activity is observable in such cells (Cotton and Brugge 1983; Ellis et al. 1988). In addition, many neuronal proteins have been identified as PTK substrates; these include synaptic vesicle proteins such as synaptophysin (Pang et al. 1988), neurotransmitter receptors such as the nicotinic acetylcholine receptor (Huganir et al. 1984) and glutamate receptors (Moss et al. 1993), and voltagegated potassium channels (Huang et al. 1993). These observations suggest that PTKs expressed in postmitotic neurons may have novel roles in regulating neuronal function in general and synaptic plasticity in particular.

Two general families of PTKs have been described (Cantley et al. 1991). One is a family of receptors for cellular growth factors such as platelet-derived growth factor (PDGF), nerve growth factor (NGF), and brain-derived neurotrophic factor (BDNF). These transmembrane receptors contain a cytosolic PTK domain that is activated upon growth-factor binding. The second is a family of cytosolic, nonreceptor kinases of which the bestcharacterized subfamily is the src-related PTKs. Although widely studied, the regulatory mechanisms of this PTK family remain poorly understood. Several members of both PTK families are expressed in post-mitotic pyramidal neurons in the hippocampus. These include the trk $B$ and trk $C$ neurotrophic factor receptors (Kang and Schuman 1995) and src kinases such as src, fyn, $a b l$, and yes (Grant et al. 1992).

INHIBITOR STUDIES The best evidence for an involvement of PTKs in LTP comes from studies with membrane-permeant PTK inhibitors. O'Dell et al. (1991b) have demonstrated that general PTK inhibitors such as genestein and lavendustin A block induction of early LTP, leaving only PTP and I-LTP. It is interesting that these compounds have no effect on established LTP. Such observations suggest a requirement for a window of PTK activity during LTP induction: Although PTK activity is necessary for the induction of E-LTP, persistent activation of PTKs is apparently not required for the expression of E-LTP.

Although this study demonstrates the neces-

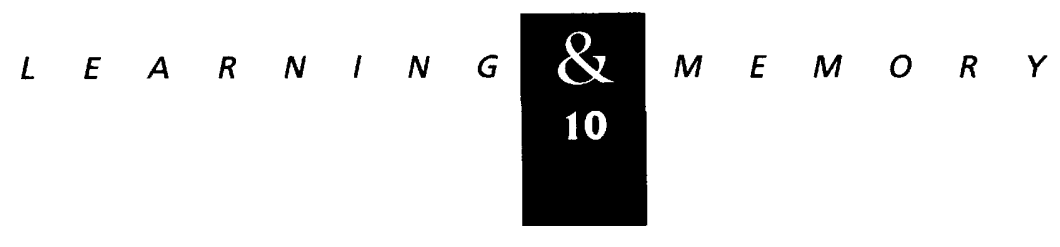


sity for PTK activity during the induction of E-LTP, it cannot provide insight into which PTKs in particular are involved. As all PTKs share a highly conserved catalytic domain, such general inhibitors have broad-spectrum effects. One approach to studying the involvement of particular PTKs in LTP is the use of transgenic mice. This variation of the "kinase inhibitor study" has been employed to investigate the role of several members of the src family of nonreceptor cytosolic PTKs. In particular, LTP has been studied in mice containing a selective knockout of either $\mathrm{p} 59^{f y n}, \mathrm{p} 61^{s r c}, \mathrm{p} 56^{\text {lyn }}$, or $\mathrm{p} 123^{\text {yes }}$. Analysis of LTP in these transgenic animals revealed that only $f y n$ mutant animals are deficient in L.TP induction (Grant et al. 1992). Specifically, the threshold for induction is increased, and in many cases LTP is absent altogether.

These results, however, should be interpreted cautiously. As PTKs are involved in cellular differentiation and proliferation, animals deficient in certain PTKs may have subtle developmental anomalies which affect the establishment of properly functioning neurons. In fact, histological examination of the hippocampus in $f y n$ mutant mice revealed that anatomical defects are present (Grant et al. 1992). Furthermore, recent evidence suggests that $f y n$ kinase is involved in axonal myelination (Umemori et al. 1994). Thus, the deficiency in LTP in the fyn mutant mice might not involve mechanisms underlying normal LTP induction.

KINASE ACTIVATOR STUDIES Recent work has demonstrated that neuronal growth factor receptors might play a role in synaptic plasticity. Application of BDNF or NT-3, ligands of neuronal trk receptors, leads to a long-lasting increase in synaptic strength (Kang and Schuman 1995). Although the biochemical mechanisms by which synaptic transmission is enhanced are unknown, the initial work suggests that a presynaptic enhancement of neurotransmitter release might be involved. And although this neurotrophin-induced potentiation partially occludes LTP (Kang and Schuman 1995), the role, if any, of these receptor PTKs in LTP remains unclear.

DIFFUSIBLE MESSENGERS

Recent years have witnessed a growing interest in the roles that small, diffusible molecules play in LTP. These messengers are permeant through the plasma membrane, and thus can participate in intercellular signaling. These molecules may play a part in sending a so-called retrograde message: We have seen that the induction of LTP seems to hinge on postsynaptic calcium influx, and there is evidence that at least part of the expression of LTP is presynaptic under certain conditions (Malinow 1991; Malgaroli et al. 1992; Stevens and Wang 1994). If so, any presynaptic component of LTP expression must depend on a "retrograde message" from the postsynaptic cell signaling that LTP has been induced. While the need for a retrograde message is still debated (Manabe and Nicoll 1994; Isaac et al. 1995), this is not the only possible role for these molecules. In addition to other, nonretrograde intercellular roles such as communication with nearby postsynaptic cells and interneurons, these molecules are likely to have autocrine effects.

We will examine the evidence supporting a signaling role in LTP for two gases, nitric oxide (NO) and carbon monoxide (CO), and two lipid molecules, arachidonic acid (AA) and platelet-activating factor (PAF). We will consider whether each meets two criteria: (1) Is its production altered during LTP? (theoretically, either an increase in a regulated factor or a decrease in a tonically generated factor could carry a message); and (2) Is its production or action required for LTP? In addition, we will examine the ability of each of these messengers to modulate the induction of LTP by determining whether it can complement a weak tetanic stimulus, normally subthreshold for LTP induction, to produce LTP.

NITRIC OXIDE Nitric oxide (NO) is a free radical produced by nitric oxide synthase (NOS) during the oxidation of arginine to citrulline. Pyramidal neurons in area CA1 of the hippocampus express both the neuronal form found throughout the brain (nNOS) and the predominantly endothelial form (eNOS). Both nNOS and eNOS are stimulated by calcium and calmodulin, which couple them to the calcium trigger for LTP. NO levels increase after LTP-inducing stimulation, an effect blocked by NOS inhibitors and removal of extracellular calcium (Chetkovich et al. 1993).

A number of studies have assessed the ability of NOS inhibitors to block the induction of LTP. Early reports indicated that NOS activity is required for LTP (O'Dell et al. 1991a; Schuman and Madison 1991; Haley et al. 1992). However, under many conditions, including at higher temperature, with stronger stimulation, and in older rats, LTP induction does not depend on NOS (Chetkovich

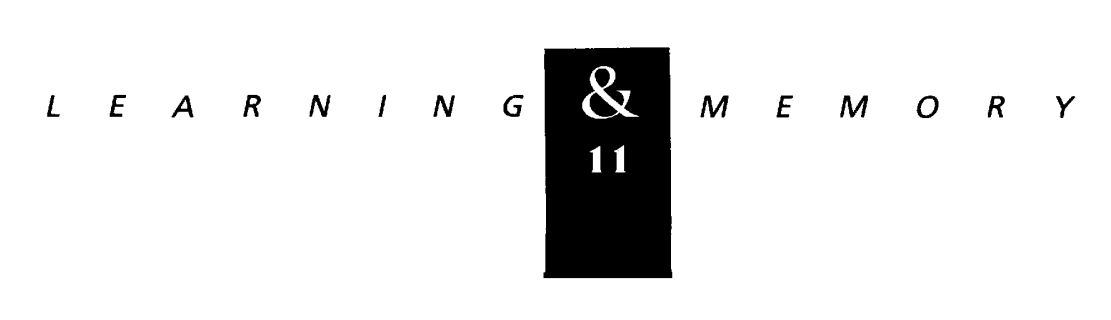


et al. 1993; Haley et al. 1993; Williams et al. 1993). Transgenic mouse studies have not helped to clarify the picture. In nNOS mutant mice, LTP is normal, but is still blocked by NOS inhibitors, presumably because of the remaining eNOS (O'Dell et al. 1994). It would be interesting to determine the effects of a double mutant, lacking both nNOS and eNOS.

Evidence of a role for NO in LTP is strengthened by considering its downstream effectors. First, NO interacts with the heme group of soluble guanylyl cyclase to stimulate the production of guanosine $3^{\prime}, 5^{\prime}$-cyclic monophosphate (cGMP). There is an NOS-dependent increase in cGMP levels during LTP (Chetkovich et al. 1993), and activity of cGMP-dependent protein kinase is required for LTP (Zhuo et al. 1994). Analogs of CGMP rescue the inhibition of LTP by NOS (Haley et al. 1992). ADP-ribosyl transferase (ADPRT) is a second possible effector of NO in LTP. CA1 pyramidal neurons contain NO-sensitive ADPRT activity, and inhibition of these enzymes prevents LTP induction (Schuman et al. 1994).

It appears that NO is capable of modulating the induction of LTP. A weak tetanus, normally subthreshold for LTP induction, leads to LTP when delivered during application of $\mathrm{NO}$ gas (Zhuo et al. 1993). More interestingly, it appears that even NO released from a single pyramidal neuron, in which LTP is induced by pairing depolarization with a weak tetanus, is capable of complementing the weak tetanus to produce LTP in neighboring cells (Schuman and Madison 1994).

Thus, while the NO story is incomplete, evidence suggests that although NO is clearly not always required for the induction of LTP, it is produced during LTP and is likely to play a modulatory role, facilitating LTP induction.

CARBON MONOXIDE CO shares several properties with NO. Although it is not a free radical, $\mathrm{CO}$ is highly diffusible and is reactive with heme groups. $\mathrm{CO}$ is produced by heme oxygenase, the enzyme which catalyzes the first step in heme degradation. Preventing $\mathrm{CO}$ production with heme oxygenase inhibitors blocks the induction of LTP (Stevens and Wang 1993; Zhuo et al. 1993). And as with NO, the application of CO gas paired with a weak tetanus does induce LTP in an NMDA receptor-independent manner (Zhuo et al. 1993).

The CO hypothesis has it weaknesses. First, the relative potency of heme oxygenase inhibitors in blocking LTP appears to correlate better with their ability to inhibit NOS than to inhibit heme oxygenase (Meffert et al. 1994). Second, heme oxygenase is a constitutively active enzyme whose activity is determined only by the amount of substrate available. It is not clear how CO production could be regulated during LTP, unless heme levels increase. In addition, it has not yet been determined whether $\mathrm{CO}$ levels increase in response to LTP-inducing stimulation. Thus, the role of $\mathrm{CO}$ in LTP remains controversial.

ARACHIDONIC ACID Arachidonic acid is a 20-carbon fatty acid that commonly occupies the sn-2 position of membrane phospholipids. It is liberated from phospholipids by the action of phospholipase $\mathrm{A}_{2}\left(\mathrm{PLA}_{2}\right)$ or the combined actions of phospholipase $\mathrm{C}$ plus diacylglycerol lipase. A number of calcium-sensitive forms of PLA $A_{2}$ have been described, and phospholipase $\mathrm{C}$ activity is regulated by activation of the metabotropic subtype of glutamate receptors. Arachidonic acid levels, measured by push-pull perfusion techniques, increase following the induction of LTP (Lynch et al. 1991).

Prevention of the production of AA with nordihydroguaiaretic acid (NDGA), an inhibitor of PI. $A_{2}$, blocks the induction of LTP (Williams and Bliss 1989; O'Dell et al. 1991a). This experiment must be interpreted with caution, however. PLA activation is the first step in the production of a series of lipid metabolites, including leukotrienes, prostaglandins, thromboxanes, and alkyl ethers like platelet-activating factor (PAF) (see below). Another caveat is that NDGA also inhibits the activity of lipoxygenase, an enzyme that produces superoxide radical as a by-product in converting AA into leukotrienes. Superoxide itself may be required for LTP (Klann et al. 1995), thus the inhibition of LTP induction by NDGA could reflect a necessity for AA as a substrate for superoxide generation rather than as a messenger per se.

AA is capable of complementing a weak tetanus, normally subthreshold for LTP induction, to produce LTP (Williams et al. 1989; O'Dell et al. 1991a), but its ability to do so is not independent of NMDA receptor activation (O'Dell et al. 1991a). This suggests that AA may act in conjunction with a second signal that is activated downstream of the NMDA receptor.

PLATELET-ACTIVATING FACTOR PAF is an alkyl ether analog of phospatidyl choline, in which the ester bond of the sn-1 fatty acid is replaced by an ether linkage. Originally named for its ability to cause platelet aggregation, PAF is also present in the CNS. Unlike other retrograde messenger candidates, PAF acts through a specific cell-surface

$$
\text { n...... }
$$


receptor. The PAF receptor is expressed throughout the cortex and in the hippocampus, where it causes increases in intracellular calcium, apparently by mobilization of intracellular stores (Bito et al. 1992).

Antagonists of the PAF receptor block the induction of LTP (del Cerro et al. 1990a; Kato et al. 1994), and PAF analogs can complement a subthreshold tetanus to produce LTP even in the presence of NMDA receptor antagonists. A major question that to date has not been addressed is whether PAF levels increase during L'TP. Evidence suggests that PAF is produced in response to ischemia and seizure, so it would seem that the brain has the capacity to regulate PAF levels, but this is an area for future study.

There remain many important, unanswered questions about the roles of these diffusible messengers in LTP. First, we have seen that in the case of each of the four messengers there is some question or controversy about its role in LTP. But more generally, the role of diffusible messengers and intercellular communication in LTP and learning is an area of active research. It remains to be seen whether and how signaling to neighboring postsynaptic cells, interneurons, or presynaptic terminals contributes to LTP.

\section{LATE LTP}

The third and final phase we will consider is late LTP (L-LTP). The hallmark of L-LTP is its dependence on protein synthesis: When inhibitors of protein synthesis are present during the initiation of LTP, normal I-LTP and E-LTP are observed, but the potentiation returns to baseline several hours after LTP induction (Frey et al. 1988). Subsequent studies have shown that transcription of RNA is also required for L-LTP (Nguyen et al. 1994). These observations are consistent with a large body of literature citing the protein synthesis-dependence of long-term, but not short-term, forms of memory (Agranoff et al. 1965; Barondes 1970; Davis and Squire 1984). The L-L.TP literature has recently been thoroughly reviewed (Huang et al. 1996), so we will provide only a brief overview of the field.

CAMP AND PKA

In the pathway leading to the development of L-LTP, the second messenger adenosine $3^{\prime}, 5^{\prime}$-cy- clic monophosphate (cAMP) plays a central role. Levels of CAMP increase for about $10 \mathrm{~min}$ following the induction of LTP (Chetkovich et al. 1991; Frey et al. 1993), and antagonists of cAMP applied during this period block the subsequent development of L-LTP (Frey et al. 1993). How does the LTP-inducing stimulus cause this rise in cAMP concentration? Calcium entry triggered by NMDA receptor activation acts in concert with calmodulin to stimulate adenylyl cyclase, the enzyme that catalyzes production of cAMP (Chetkovich and Sweatt 1993). In addition, activation of the $G$ proteincoupled D1/D5 class of dopamine receptors is required for the LTP-associated increase in cAMP (Frey et al. 1993).

Downstream of cAMP, it is known that PKA is activated during L'TP (Roberson and Sweatt 1993). This activation follows the time course of the elevation in CAMP and does not persist during the expression of either E-LTP or L-LTP (Roberson and Sweatt 1996). Together with data indicating that PKA inhibitors block L-LTP induction (Frey et al. 1993; Matthies and Reymann 1993), these data implicate a role for PKA in the induction of L-LTP. However, the identities of the substrates phosphorylated by PKA during the induction of L-LTP remain unknown. As mentioned above, PKA inhibitors also affect the induction of E-LTP, and it is suspected that phosphatase inhibition via inhibitor-1 phosphorylation may be one role of PKA. Such a mechanism could also be involved in L-LTP induction.

CREB AND GENE EXPRESSION

Another possibility, given the dependence of L-LTP on RNA and protein synthesis, is that PKA might induce changes in gene expression via phosphorylation of the transcription factor CREB (see Huang et al. 1996). CREB activates the transcription of genes with an upstream cAMP response element (CRE) when phosphorylated by PKA or CaMKII at a specific serine residue, $\operatorname{Ser}_{133}$ (Yamamoto et al. 1988; Dash et al. 1991). In fact, there is good evidence of a role for CREB in LTP. Impey et al. (1996) demonstrated an increase in CRE-mediated transcription during the induction of LTP. It is also known that mRNAs of several CRE-linked genes, including c-fos and proenkephalin, increase during LTP (Morris et al. 1988; Kaczmarek 1992; Mackler et al. 1992). Furthermore, it has been demonstrated that phosphorylation of

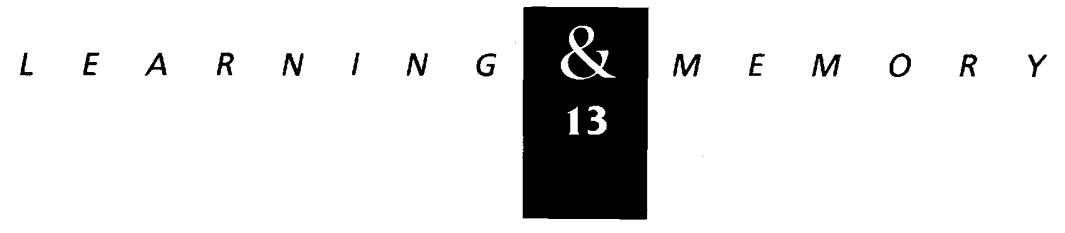


CREB at $\operatorname{Ser}_{133}$ increases during L'TP (Deisseroth et al. 1996; Impey et al. 1996). Finally, transgenic mice lacking CREB display deficiencies in longterm memory and LTP (Bourtchuladze et al. 1994). Thus, it seems clear that CREB plays a role in the induction of LTP.

One important question is whether its role is exclusively in L-LTP, or whether it is also critical for earlier phases. Activation of CREB also occurs during the induction of long-term depression and when only E-LTP is induced (Deisseroth et al. 1996; Impey et al. 1996), and it is unclear whether the LTP deficits of CREB mutant mice are selective for the late phase in area CA1 (Bourtchuladze et al. 1994). In addition, it is also unclear whether the activation of CREB is mediated by PKA or CaMKII (Deisseroth et al. 1996). Thus, it may be that other PKA substrates besides CREB are also important for the induction of L-LTP.

The dependence of L-LTP on RNA and protein synthesis, coupled with the observation that LTP is associated with altered patterns of transcription and the involvement of CREB, have led to the hypothesis that L-LTP depends on changes in gene expression. There are a few additional points to keep in mind when considering this hypothesis. First, it does not exclude the possibility that autonomous kinase activity contributes to L-LTP; the autonomous activation of PKC or CaMKII associated with E-LTP may require some protein synthesis to be sustained into L-LTP. Second, the available data do not discriminate between an induction and an expression role for changes in gene expression. For example, a transient pulse of "building blocks" may be required for the induction of L-LTP, while playing no role in its expression (Lisman 1995). If the new gene products were to play a role in LTP expression, then the new pattern of expression would have to last as long as the phase it supports. As alluded to in the introduction, this sort of persistent cellular change must have some underlying persistent biochemical basis, for example the autonomous activation of a nuclear kinase. Finally, changes in gene expression per se are insufficient to explain LTP. As LTP is a synapse-specific phenomenon, any change in gene expression must involve a mechanism for addressing the information to the appropriate synapse (Lisman 1995). A potentiated synapse must have some resident signal to enable it to receive the newly made gene product. Thus, even if changes in gene expression are required for LTP, there must be persistent signals at the synapse.
Our discussion of L-LTP has focused on induction mechanisms because the expression mechanisms for L-LTP are not understood. It will be interesting to see how those mechanisms relate to the mechanisms for E-LTP expression, and whether even later stages supersede L-LTP.

\section{Interactions between the Phases of LTP}

Thus far we have seen how the mechanisms contributing to each LTP phase can operate independently. Given the large number of second messengers, protein kinases, and effectors involved in LTP, however, it is likely that the mechanisms might interact with one another.

For example, consider a likely interaction between a mechanism for the expression of E-LTP and the induction of L-LTP. As discussed above, CaMKII has a role in phosphorylating effectors that contribute to the expression of E-LTP. In addition, as seen in the section on L-LTP, CaMKII may play a role in the induction of L-LTP through its effects on CREB phosphorylation. Therefore, one mechanism, activation of CaMKII, may contribute to the induction and expression of two temporally distinct phases of LTP. There likely are many other examples of interactions between the induction and/or expression mechanisms for the various phases of LTP.

This example is based on known biochemical mechanisms that directly suggest likely sites of interaction between phases of LTP. However, simply by observing the physiologic properties of LTP, theoretical considerations arise, implying that the multiple mechanisms for LTP induction and expression interact. By and large, once a neuron receives a potentiating signal, the magnitude of the potentiation remains constant (see Fig. 1). How is it that LTP maintains a constant magnitude as the various phases wax and wane? There are two fundamental issues with which the neuron must deal (Fig. 3). It must ensure that (1) during the transition between phases, the potentiation is maintained at a constant level (the Timing Problem), and (2) that after the transition, the degree of potentiation produced by the second phase is the same as it was in the earlier phase (the Magnitude Problem).

There are three fundamentally different, general models by which the neuron might solve

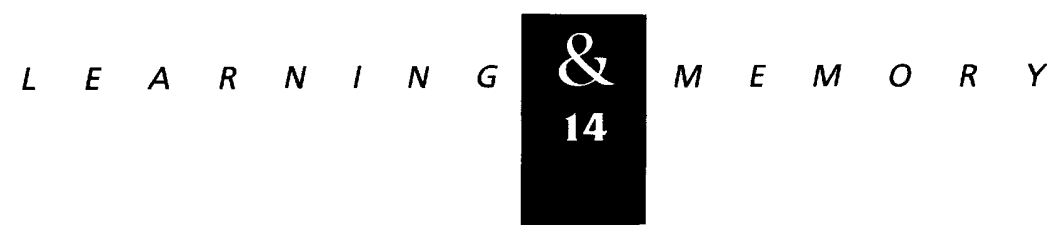




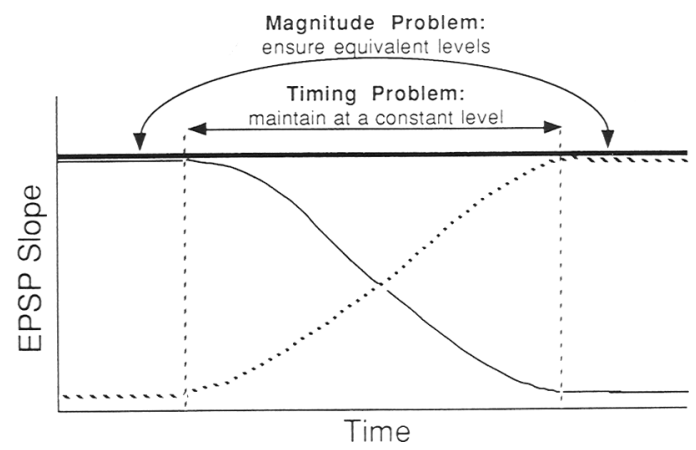

Figure 3: Schematic diagram of the two challenges of phase succession, presented as a graph of potentiation (EPSP slope) over time. Thin solid line: potentiation contributed by an early phase; dotted line: by a later phase. Dark solid line: the constant level of potentiation that must be produced by the two transitioning phases. The Timing Problem arises during the transition: The potentiation must be maintained at a constant level. The Magnitude Problem pertains to the degree of potentiation before and after the transition, which also must be equal.

these challenges to produce a constant, maintained potentiation (Table 1 ).

\section{THE SIMPLE SUMMMATION MODEL.}

First, it is possible that the time constants for the onset and decay of the various potentiating mechanisms, and the magnitude of their maximum effects, are preprogrammed as intrinsic properties of the various component molecules. In this simple summation model, the mechanisms for each phase operate completely independently of each other but sum to a constant level over time. As for the Timing Problem, the decay of one phase is exactly matched by the onset of the next phase, and thus LTP remains constant from one phase to the next. This consideration leads to the prediction that the decay of any single phase, if it were isolated, would be complementary to the onset of the next phase. With regard to the Magnitude Problem, in this model the degree of potentiation in each phase is equal by virtue of the cascades' intrinsic properties, so that the two phases plateau at the same levels.

As LTP is stably expressed under widely divergent conditions of temperature and metabolic state, this model predicts that the kinetics of each phase have the same dependence on temperature $\left(Q_{10}\right)$, ATP concentration, cofactor concentration, and so on. Thus, every step in the various induction and expression cascades must change by similar proportions under different conditions. Although not theoretically impossible, this requirement seems unlikely and is the major shortcoming of this model.

\section{THE CROSS-TALK MODEL}

Some of the limitations of the simple summation model would be relieved if it were postulated that the phases directly affected each other. In this cross-talk model, the new phase has a negative feedback mechanism to turn off expression of the earlier phase; this ensures that the beginning of the new phase coincides with the onset of the old phase's decay. But the new phase is also dependent on a positive feedforward signal from the old phase for its induction, which ensures that induction of the new phase does not continue past the point where the old phase has decayed completely. Interacting in this fashion over time solves the Timing Problem, but still does not account for the Magnitude Problem.

The following example serves to illustrate this model. Suppose that E-LTP is subserved by an autonomously activated kinase phosphorylating receptors present at the synapse, and that L-LTP is subserved by the increased expression and subsequent arrival of a new type of protein kinase. Suppose that the new kinase, once it is activated, can inactivate the old kinase by phosphorylating it. This is the negative feedback signal that ensures that once L-LTP begins, E-LTP starts to decay. Now suppose that the new kinase arrives at the synapse in an inactive state and is turned on by the old, autonomously active kinase. This feedforward signal ensures that once E-LTP decays completely, there is no further induction of L-LTP.

In this example both phases operate in the same subcellular compartment. A model of this sort can deal with the quandary of LTP being presynaptic at one time point and postsynaptic at another if the feedforward and feedback signal are membrane-permeant.

\section{THE SATURATION MODEL}

In the simple summation and cross-talk models, the expression mechanism of each phase op-

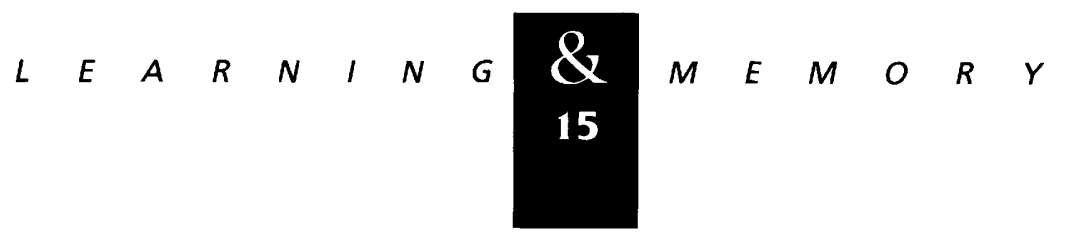


Roberson et al.

Table 1: Summary of the three models for phase transitions

\begin{tabular}{|c|c|c|c|}
\hline Model & $\begin{array}{l}\text { Distinguishing } \\
\text { characteristics }\end{array}$ & $\begin{array}{l}\text { Problem explicitly } \\
\text { solved by model }\end{array}$ & Predictions \\
\hline $\begin{array}{l}\text { Simple } \\
\text { summation }\end{array}$ & $\begin{array}{l}\text { Postulates solution on } \\
\text { the basis of intrinsic } \\
\text { properties }\end{array}$ & Neither problem & $\begin{array}{l}\text { When sequential phases are } \\
\text { isolated from one another, } \\
\text { decay of first is } \\
\text { complementary to onset of } \\
\text { second } \\
\text { The dependence of all } \\
\text { involved processes on } \\
\text { metabolic variables } \\
\text { (temperature, ATP } \\
\text { concentration, etc.) is similar }\end{array}$ \\
\hline Cross talk & $\begin{array}{l}\text { Feedforward and } \\
\text { feedback } \\
\text { mechanisms }\end{array}$ & Timing Problem & $\begin{array}{l}\text { Direct molecular cross talk is } \\
\text { present between mechanisms }\end{array}$ \\
\hline Saturation & $\begin{array}{l}\text { Saturation of an } \\
\text { effector }\end{array}$ & $\begin{array}{l}\text { Magnitude Problem (abates } \\
\text { Timing Problem) }\end{array}$ & $\begin{array}{l}\text { Underlying mechanisms } \\
\text { overlap in time } \\
\text { Synaptic version only: There is } \\
\text { no PTP or PPF at a synapse } \\
\text { with LTP } \\
\text { Molecular version only: There } \\
\text { are no transitions from entire } \\
\text { presynaptic to entirely } \\
\text { postsynaptic and vice versa, } \\
\text { unless some effector } \\
\text { spanning the synaptic cleft is } \\
\text { present in both } \\
\text { compartments }\end{array}$ \\
\hline
\end{tabular}

erates independently on its final effector, and constancy must be achieved by matching the decay of one phase with a corresponding increase in the subsequent phase. However, there is another strategy the neuron might use to achieve constancy. In the saturation model, two expression mechanisms converge on a single entity that is maximally activated by either signal alone, such that even the presence of both potentiating signals does not drive synaptic transmission beyond a given level. The effector is driven to its maximum level when either the first or the second potentiating signal is present, or both.

The saturation model provides an explicit solution to the Magnitude but not the Timing Problem. However, in the saturation model, there is no need for precise temporal matching of the onset and decay of succeeding phases, as long as the effector is always driven past the threshold for saturation. Thus the saturation model abates the Tim- ing Problem, requiring only that the phases overlap to a sufficient extent.

There are two slightly different versions of the saturation model, which make additional, specific predictions. These versions differ in the nature of the saturated effector. In the synaptic version, the entire synapse is postulated to be driven maximally by each phase. That is, an earlier phase and a later phase both put the synapse in a fully "on" state, such that their combined effects are no greater than the individual effects. One appeal of this model is that it easily accounts for LTP that is exclusively postsynaptic at one time point and exclusively presynaptic at another. In addition, the model makes a unique prediction. As a synapse undergoing LTP is maximally driven, no other plasticity can occur at that synapse; it is occluded. That is, in the synaptic version of the saturation model, PTP and paired-pulse facilitation can occur only at synapses that have not undergone LTP.

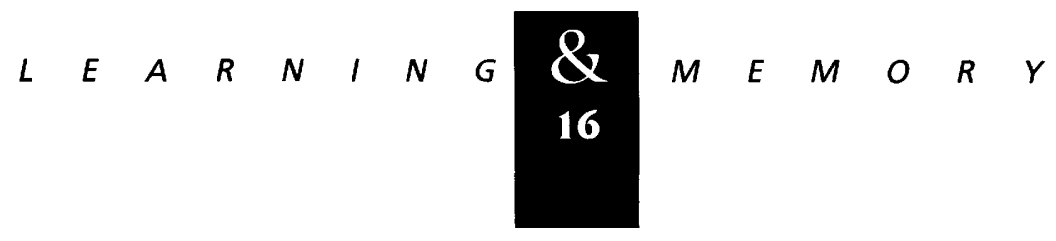


In the molecular version, the saturated effector is an individual protein or complex of proteins. For example, suppose that E-LTP is subserved by a kinase phosphorylating and maximally activating a particular subtype of glutamate receptor in the postsynaptic spine. When phosphorylated, the current through the receptor is maximal and greater than when the receptor is unphosphorylated. Now suppose that L-LTP is subserved by expression of a novel modulatory subunit of the same subtype of receptor that likewise, when available, causes the current through the channel to be maximal. The effect of the new subunit is the same as the effect of phosphorylation, and the two are not additive; either alone produces maximal conductance. As long as a saturating level of the novel subunit appeared at the spine before the modulatory kinase activity had decayed, LTP would be expressed at a constant level over time. A similar model could of course be formulated using a presynaptic neurotransmitter release site for the potentiating effect.

This type of model serves quite well to explain LTP that is exclusively presynaptic, exclusively postsynaptic, or a mixture of both. If LTP is entirely presynaptic at one time point but entirely postsynaptic at another, this model predicts that a single effector molecule (or complex) must be present that can be both simultaneously and maximally driven by either a presynaptic or a postsynaptic signaling molecule. Although to our knowledge no such complex has been demonstrated yet, it is certainly possible that various cell-surface molecules may exist that can serve such a function.

The three models have been separated here for purposes of clarity. Of course, in LTP the real solutions to the Timing and Magnitude Problems may draw on each of the three and comprise some hybrid model.

\section{Conclusion}

The last decade or so has brought to light copious new information about mechanisms involved in LTP, and revealed a perhaps unexpected complexity in its biochemistry. One might have anticipated, a priori, that LTP would be explained by a single, monolithic mechanism. So why are so many signaling cascades apparently required? The fact that LTP is mediated by a series of phases with distinct mechanisms inherently increases the complexity of LTP. Furthermore, as we have seen, each phase has an induction component that by nature is transient and serves to bring about an expression component that directly supports LTP; the induction and expression mechanisms of each phase may be distinct. Finally, we have seen that additional mechanisms may be required to mediate the interactions of successive phases. Might there still be some hope for simplicity in the possibility that each phase converges on the same effector, culminating by producing the same result? Our understanding of the various expression mechanisms is far too incomplete to rule out this possibility, although the observation that after several weeks, LTP in vivo is associated with structural changes that do not happen on the shorter time scale of early phases may argue against the possibility.

The Holy Grail of LTP remains a complete understanding of expression mechanisms, the actual means underlying the observed persistent effect. As biochemists, we work from the premise that any lasting phenotypic effect must be supported by a lasting change in the cell's molecules, most likely its proteins. The search for these lasting molecular changes has been difficult. Although it has been suggested that changes in gene expression represent the expression mechanisms for L-LTP, the means by which these changes are made lasting has not been demonstrated, nor has the persistent synaptic signal that would be required to receive the new gene products specifically at potentiated synapses. Similarly, the persistent biochemical changes that would be associated with LTP-associated changes in synapse structure or activation of silent synapses have not been identified. The only well-documented example of a sustained molecular change in LTP is the autonomous activation of protein kinases, and even this does not comprise the complete description of an LTP expression mechanism, as the substrates phosphorylated by these kinases remain unknown. Finally, even if the expression mechanisms of the phases of LTP were to be miraculously revealed, our understanding would remain incomplete, for, as we have seen, it is likely that the mechanisms for each phase interact in order to maintain constancy in the level of potentiation.

How a transient signal can generate a persistent change is a fascinating puzzle from the biochemist's point of view. We have identified many of the pieces and arranged some, but are only beginning to appreciate the complete picture.

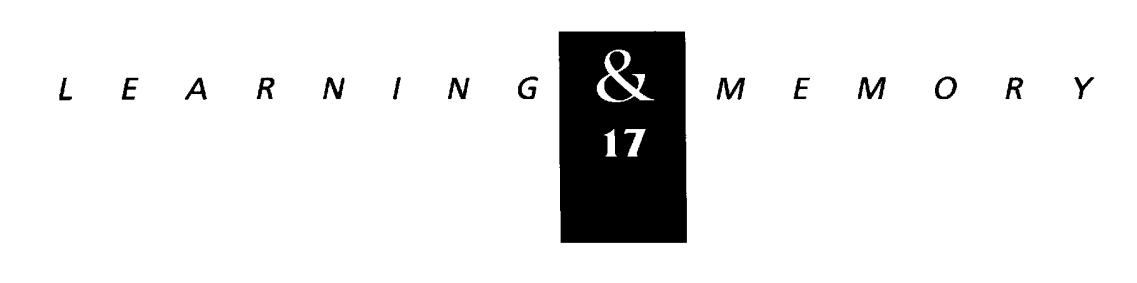




\section{Acknowledgments}

We are grateful to John Assad, Saurabh Sinha, Coleen Atkins, Nikos Logothetis, John Maunsell, and Read Montague for many helpful discussions and insights, as well as comments on the manuscript.

The publication costs of this article were defrayed in part by payment of page charges. This article must therefore be hereby marked "advertisement" in accordance with 18 USC section 1734 solely to indicate this fact.

\section{References}

Abeliovich, A., C. Chen, Y. Goda, A.J. Silva, C.F. Stevens, and S. Tonegawa. 1993. Modified hippocampal long-term potentiation in PKC $\gamma$-mutant mice. Cell 75: 1253-1262.

Agranoff, B.W., R.E. Davis, and J.J. Brink. 1965. Memory fixation in the goldfish. Proc. Natl. Acad. Sci. 54: 788-793.

Akers, R.F. and A. Routtenberg. 1985. Protein kinase C phosphorylates a $47 \mathrm{M}_{\mathrm{r}}$ protein ( $\mathrm{F} 1$ ) directly related to synaptic plasticity. Brain Res. 334: 147-151.

Akers, R.F., D.M. Lovinger, P.A. Colley, D.J. Linden, and A. Routtenberg. 1986. Translocation of protein kinase $C$ activity may mediate hippocampal long-term potentiation. Science 231: $587-589$.

Aloyo, Y.J., H. Zwiers, and W.H. Gispen. 1982. B-50 protein kinase and kinase $C$ in rat brain. Prog. Brain Res. 54: 303-315.

Amador, M. and J.A. Dani. 1991. Protein kinase inhibitor, $\mathrm{H}-7$, directly affects $\mathrm{N}$-methyl-D-aspartate receptor channels. Neurosci. Lett. 124: 251-255.

Barondes, S.H. 1970. Cerebral protein synthesis inhibitors block long-term memory. Int. Rev. Neurobiol. 12: 177-205.

Bashir, Z.I., B. Tam, and G.L. Collingridge. 1990. Activation of the glycine site in the NMDA receptor is necessary for the induction of LTP. Neurosci. Lett. 108: 261-266.

Baudier, J., C. Bronner, D. Kligman, and R.D. Cole. 1989. Protein kinase $\mathrm{C}$ substrates from bovine brain. Purification and characterization of neuromodulin, a neuron-specific calmodulin-binding protein. J. Biol. Chem. 264: 1824-1828.

Baudier, J., J.C. Deloulme, A. van Dorsselaer, D. Black, and H.W. Matthes. 1991. Purification and characterization of a brain-specific protein kinase $C$ substrate, neurogranin ( $p 17)$. Identification of a consensus amino acid sequence between neurogranin and neuromodulin (GAP43) that corresponds to the protein kinase $C$ phosphorylation site and the calmodulin-binding domain. J. Biol. Chem. 266: 229-237.

Bazzi, M.D. and G.L. Nelsestuen. 1988. Constitutive activity of membrane-inserted protein kinase C. Biochem. Biophys. Res. Comm. 152: 336-343.

Bito, H., M. Nakamura, Z. Honda, T. Izumi, T. Iwatsubo, Y. Seyama, A. Oguura, Y. Kudo, and T. Shimizu. 1992. Platelet-activating factor (PAF) receptor in rat brain: PAF mobilizes intracellular calcium in hippocampal neurons. Neuron 9: 285-294.

Blitzer, R.D., T. Wong, R. Nouranifar, R. lyengar, and E.M. Landau. 1995. Postsynaptic cAMP pathway gates early LTP in hippocampal CA1 region. Neuron 15: 1403-1414.

Böhme, G.A., C. Bon, J.-M. Stutzmann, A. Doble, and J.-C. Blanchard. 1991. Possible involvement of nitric oxide in long-term potentiation. Eur. J. Pharmacol. 199: 379-381.

Bourtchuladze, R., B. Frenguelli, J. Blendy, D. Cioffi, G. Schutz, and A.J. Silva. 1994. Deficient long-term memory in mice with a targeted mutation of the CAMP-responsive element-binding protein. Cell 79: 59-68.

Butler, L.S., A.J. Silva, A. Abeliovich, Y. Watanabe, S. Tonegawa, and J.O. McNamara. 1995. Limbic epilepsy in transgenic mice carrying a $\mathrm{Ca}^{2+} /$ calmodulin-dependent kinase II alpha-subunit mutation. Proc. Natl. Acad. Sci. 92: 6852-6855.

Cantley, L.C., K.R. Auger, C. Carpenter, B. Duckworth, A. Graiani, R. Kapeller, and S. Soltoff. 1991. Oncogenes and signal transduction. Cell 64: 281-302.

Castagna, M., Y. Takai, K. Kaibuchi, K. Sano, and U. Kikkawa. 1982. Direct activation of calcium-activated, phospholipid-dependent protein kinase by tumor-promoting phorbol esters. J. Biol. Chem. 257: 7847-7851.

Chen, S.-J., E. Klann, and J.D. Sweatt. 1993. Maintenance of LTP is associated with an increase in the phosphorylation of neurogranin protein. Soc. Neurosci. Abstr. 19: 1707.

Chetkovich, D.M. and J.D. Sweatt. 1993. NMDA receptor activation increases cyclic AMP in area CA1 of the hippocampus via calcium/calmodulin stimulation of adenylyl cyclase. J. Neurochem. 61: 1933-1942.

Chetkovich, D.M., R. Gray, D. Johnston, and J.D. Sweatt. 1991. N-methyl-D-aspartate receptor activation increases cAMP levels and voltage-gated $\mathrm{Ca}^{2+}$ channel activity in area CA1 of hippocampus. Proc. Natl. Acad. Sci. 88: 6467-6471.

Chetkovich, D.M., E. Klann, and J.D. Sweatt. 1993. Nitric oxide synthase-independent long-term potentiation in area CA1 of hippocampus. NeuroReport 4: 919-922.

Coan, E.J., W. Saywood, and G.L. Collingridge. 1987. MK-801 blocks NMDA receptor-mediated synaptic transmission and long term potentiation in rat hippocampal slices. Neurosci. Lett. 80: 111-114.

Colley, P.A., F.-S. Sheu, and A. Routtenberg. 1990. Inhibition of protein kinase C blocks two components of LTP persistence, leaving initial potentiation intact. J. Neurosci. 10: $3353-3360$.

Collingridge, G.L., S.J. Kehl, and H. McLennan. 1983. Excitatory amino acids in synaptic transmission in the Schaffer collateral-commissural pathway of the rat hippocampus. J. Physiol. 334: 33-46.

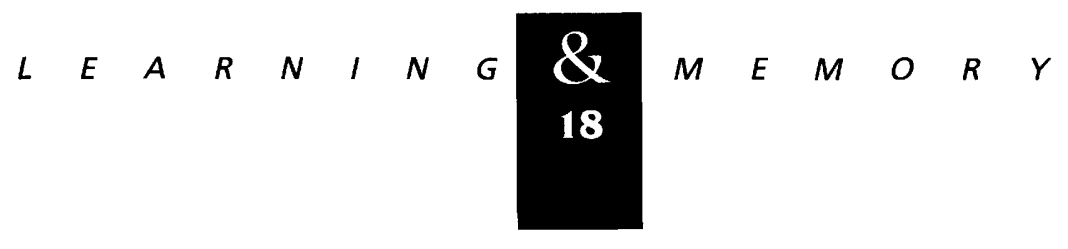


Cotton, P.C. and J.S. Brugge. 1983. Neural tissues express high levels of the cellular src gene product pp60 (c-src). Mol. Cell. Biol. 3: 1157-1162.

Crick, F. 1984. Memory and molecular turnover. Nature 312: 101.

Dash, P.K., K.A. Karl, M.A. Colicos, R. Prywes, and E.R. Kandel. 1991. cAMP response element-binding protein is activated by $\mathrm{Ca}^{2+} /$ calmodulin- as well as CAMP-dependent protein kinase. Proc. Natl. Acad. Sci. 88: 5061-5065.

Davis, H.P. and L.R. Squire. 1984. Protein synthesis and memory: A review. Psychol. Bull. 96: 518-559.

Deisseroth, K., H. Bito, and R.W. Tsien. 1996. Signaling from synapse to nucleus: Postsynaptic CREB phosphorylation during multiple forms of hippocampal synaptic plasticity. Neuron 16: 89-101.

Dekker, L.V., P.N. de Graan, A.B. Oestreicher, D.H.G. Versteeg, and W.H. Gispen. 1989a. Inhibition of noradrenaline release by antibodies to B-50 (GAP43). Nature 342: 74-76.

Dekker, L.V., P.N. de Graan, D.H.G. Versteeg, A.B. Oestreicher, and W.H. Gispen. 1989b. Phosphorylation of B-50 (GAP43) is correlated with neurotransmitter release in rat hippocampal slices. I. Neurochem. 52: 24-30.

del Cerro, S., A. Arai, and G. Lynch. 1990a. Inhibition of long-term potentiation by an antagonist of platelet-activating factor receptors. Behav. Neural Biol. 54: 213-217.

del Cerro, S., J. Larson, M.W. Oliver, and G. Lynch. 1990b. Development of hippocampal long-term potentiation is reduced by recently introduced calpain inhibitors. Brain Res. 530: 91-95.

Denny, J.B., J. Polan-Curtain, A. Ghuman, M.J. Wayner, and D.L. Armstrong. 1990a. Calpain inhibitors block long-term potentiation. Brain Res. 534: 317-320.

Denny, J.B., J. Polan-Curtain, S. Rodriguez, M.J. Wayner, and D.L. Armstrong. 1990b. Evidence that protein kinase $M$ does not maintain long-term potentiation. Brain Res. 534: $201-208$.

Edwards, F.A. 1995. LTP_A structural model to explain the inconsistencies. Trends Neurosci. 18: 250-255.

Ellis, P.D., N. Bissoon, and J.W. Gurd. 1988. Synaptic protein tyrosine kinase: Partial characterization and identification of endogenous substrates. I. Neurochem. 51: 611-620.

Fedorov, N.B., P. Pasinelli, A.B. Oestreicher, P.N. de Graan, and K.G. Reymann. 1995. Antibodies to postsynaptic PKC substrate neurogranin prevent long-term potentiation in hippocampal CA1 neurons. Eur. J. Neurosci. 7: 819-822.

Feng, T.P. and J.H. Wang. 1992. PKC(19-31) and CaMKII(273-302) given together intracellularly to the postsynaptic neuron synergistically block LTP in hippocampal CA1 region. Soc. Neurosci. Abstr. 18: 760.

Finn, R.C., M. Browning, and G. Lynch. 1980. Trifluoperazine inhibits hippocampal long-term potentiation and the phosphorylation of a 40,000 dalton protein. Neurosci. Lett. 19: 103-108.

Flint, A.J., R.D. Paladini, and D.E. Koshland, Jr. 1990. Autophosphorylation of protein kinase $\mathrm{C}$ at three separated regions of its primary sequence. Science 249: 408-411.

Frey, U., M. Krug, K.G. Reymann, and H. Matthies. 1988. Anisomycin, an inhibitor of protein synthesis, blocks late phases of LTP phenomena in the hippocampal CA1 region in vitro. Brain Res. 452: 57-65.

Frey, U., Y.-Y. Huang, and E.R. Kandel. 1993. Effects of CAMP simulate a late stage of LTP in hippocampal CA1 neurons. Science 260: 1661-1664.

Fukunaga, K., L. Stoppini, E. Miyamoto, and D. Muller. 1993. Long-term potentiation is associated with an increased activity of calcium/calmodulin-dependent protein kinase II. J. Biol. Chem. 268: 7863-7867.

Gianotti, C., M.G. Nunzi, W.H. Gispen, and R. Corradetti. 1992. Phosphorylation of the presynaptic protein B-50 (GAP-43) is increased during electrically induced long-term potentiation. Neuron 8: 843-848.

Grant, S.G.N., T.J. O'Dell, K.A. Karl, P.L. Stein, P. Soriano, and E.R. Kandel. 1992. Impaired long-term potentiation, spatial learning, and hippocampal development in fyn mutant mice. Science 258: 1903-1910.

Greenberg, D.A., C.L. Carpenter, and R.O. Messing. 1987. Interaction of calmodulin inhibitors and protein kinase $C$ inhibitors with voltage-dependent calcium channels. Brain Res. 404: 401-404.

Haley, J.E., G.L. Wilcox, and P.F. Chapman. 1992. The role of nitric oxide in hippocampal long-term potentiation. Neuron 8: 211-216.

Haley, J.E., P.L. Malen, and P.F. Chapman. 1993. Nitric oxide synthase inhibitors block long-term potentiation induced by weak but not strong tetanic stimulation at physiological brain temperature in rat hippocampal slices. Neurosci. Lett. 160: 85-88.

Hannun, Y.A. and R.M. Bell. 1990. Rat brain protein kinase C. Kinetic analysis of substrate dependence, allosteric regulation, and autophosphorylation. J. Biol. Chem.

265: $2962-2972$.

Hannun, Y.A., C.R. Loomis, A.H. Merrill, Jr., and R.M. Bell. 1986. Sphingosine inhibition of protein kinase $C$ activity and of phorbol dibutyrate binding in vitro and in human platelets. J. Biol. Chem. 261: 12604-12609.

Harris, E.W., A.H. Ganong, and C.W. Cotman. 1984. Long-term potentiation in the hippocampus involves

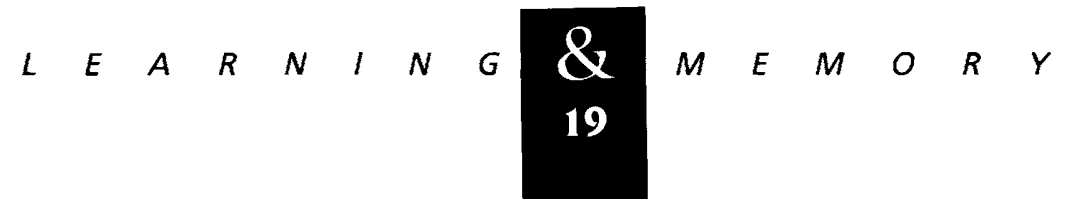


activation of $\mathrm{N}$-methyl-D-aspartate receptors. Brain Res. 323: $132-137$.

Harvey, J. and G.L. Collingridge. 1992. Thapsigargin blocks the induction of long-term potentiation in rat hippocampal slices. Neurosci. Lett. 139: 197-200.

Hidaka, H. and R. Kobayashi. 1992. Pharmacology of protein kinase inhibitors. Ann. Rev. Pharmacol. Toxicol. 32: 377-397.

Hidaka, H., M. Inagaki, S. Kawamoto, and Y. Sasaki. 1984. Isoquinolinesulfonamides, novel and potent inhibitors of cyclic nucleotide dependent protein kinase and protein kinase C. Biochemistry 23: 5036-5041.

Hu, G.Y., O. Hvalby, S.I. Walaas, K.A. Albert, P. Skjeflo, P. Andersen, and P. Greengard. 1987. Protein kinase C injection into hippocampal pyramidal cells elicits features of long term potentiation. Nature 328: $426-429$.

Huang, K.P., K.J. Chan, T.J. Singh, H. Nakabayashi, and F.L. Huang. 1986. Autophosphorylation of rat brain $\mathrm{Ca}^{2+}$-activated and phospholipid-dependent protein kinase. I. Biol. Chem. 261: 12134-12140.

Huang, X.Y., A.D. Morielli, and E.G. Peralta. 1993. Tyrosine kinase-dependent suppression of a potassium channel by the $\mathrm{G}$ protein-coupled $\mathrm{m} 1$ muscarinic acetylcholine receptor. Cell 75: 1145-1156.

Huang, K.P. and F.L. Huang. 1986. Conversion of protein kinase $\mathrm{C}$ from a $\mathrm{Ca}^{2+}$-dependent to an independent form of phorbol ester-binding protein by digestion with trypsin. Biochem. Biophys. Res. Comm. 139: 320-326.

Huang, Y.-Y. and E.R. Kandel. 1994. Recruitment of long-lasting and protein kinase A-dependent long-term potentiation in the CA1 region requires repeated tetanization. Learn. \& Mem. 1: 74-82.

1995. D1/D5 receptor agonists induce a protein synthesis-dependent late potentiation in the CA1 region of the hippocampus. Proc. Natl. Acad. Sci. 92: 2446-2450.

Huang, Y.-Y., X.C. Li, and E.R. Kandel. 1994. cAMP contributes to mossy fiber LTP by initiating both a covalently mediated early phase and macromolecular synthesis-dependent late phase. Cell 79: 69-79.

Huang, Y.-Y., P.V. Nguyen, T. Abel, and E.R. Kandel. 1996. Long-lasting forms of synaptic plasticity in the mammalian hippocampus. Learn. \& Mem. (in press).

Huber, K.M., M.D. Mauk, C. Thompson, and P.T. Kelly. 1995. A critical period of protein kinase activity after tetanic stimulation is required for the induction of long-term potentiation. Learn. \& Mem. 2: 81-100.

Huganir, R.L., K. Miles, and P. Greengard. 1984. Phosphorylation of the nicotinic acetylcholine receptor by an endogenous tyrosine-specific protein kinase. Proc. Natl. Acad. Sci. 81: 6968-6972.
Hvalby, O., K. Reymann, and P. Andersen. 1988. Intracellular analysis of potentiation of CA1 hippocampal synaptic transmission by phorbol ester application. Exp. Brain Res. 71: 588-596.

Hvalby, O., H.C. Hemmings, Jr., O. Paulsen, A.J. Czernik, A.C. Nairn, J.M. Godfraind, V. Jensen, M. Raastad, J.F. Storm, P. Andersen, and P. Greengard. 1994. Specificity of protein kinase inhibitor peptides and induction of long-term potentiation. Proc. Natl. Acad. Sci. 91: 4761-4765.

Impey, S., M. Mark, E.C. Villacres, S. Poser, C. Chavkin, and D.R. Storm. 1996. Induction of CRE-mediated gene expression by stimuli that generate long-lasting LTP in area CA1 of the hippocampus. Neuron 16: 973-982.

Inoue, M., A. Kishimoto, Y. Takai, and Y. Nishizuka. 1977. Studies on a cyclic nucleotide-independent protein kinase and its proenzyme in mammalian tissues. II. Proenzyme and its activation by calcium-dependent protease from rat brain. I. Biol. Chem. 252: 7610-7616.

Isaac, J.T., R.A. Nicoll, and R.C. Malenka. 1995. Evidence for silent synapses: Implications for the expression of LTP. Neuron 15: 427-434.

Ito, I., H. Hidaka, and H. Sugiyama. 1991. Effects on $\mathrm{KN}-62$, a specific inhibitor of calcium/calmodulin-dependent protein kinase II, on long-term potentiation in the rat hippocampus. Neurosci. Lett. 121: 119-121.

Kaczmarek, L. 1992. Expression of c-fos and other genes encoding transcription factors in long-term potentiation. Behav. Neural Biol. 57: 263-266.

Kamiya, H. and R.S. Zucker. 1994. Residual $\mathrm{Ca}^{2+}$ and short-term synaptic plasticity. Nature 371: 603-606.

Kamiya, H., S. Sawada, and C. Yamamoto. 1988. Additive feature of long-term potentiation and phorbol ester-induced synaptic enhancement in the mossy fiber-CA3 synapse. Exp. Neurol. 102: 314-317.

Kang, H. and E.M. Schuman. 1995. Long-lasting neurotrophin-induced enhancement of synaptic transmission in the adult hippocampus. Science 267: 1658-1662.

Kato, K., G.D. Clark, N.G. Bazan, and C.F. Zorumski. 1994 Platelet-activating factor as a potential retrograde messenger in CA1 hippocampal long-term potentiation. Nature 367: 175-179.

Kishimoto, A., N. Kajikawa, M. Shiota, and Y. Nishizuka. 1983. Proteolytic activation of calcium-activated, phospholipid-dependent protein kinase by calcium-dependent neutral protease. J. Biol. Chem. 258: $1156-1164$.

Kishimoto, A., K. Mikawa, K. Hashimoto, 1. Yasuda, S. Tanaka, M. Tominaga, T. Kuroda, and Y. Nishizuka. 1989. Limited proteolysis of protein kinase $\mathrm{C}$ subspecies by calcium-dependent neutral protease (calpain). J. Biol. Chem. 264: 4088-4092.

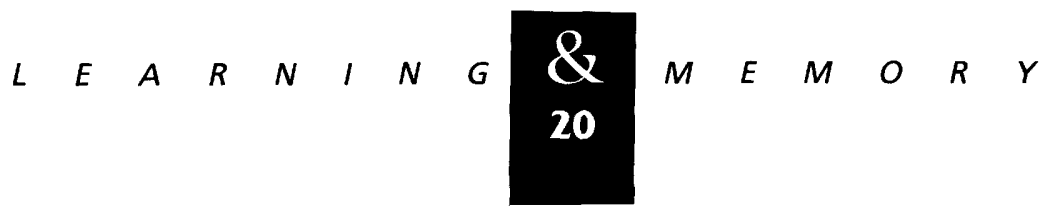


Klann, E., S.-J. Chen, and J.D. Sweatt. 1991. Persistent protein kinase activation in the maintenance phase of long-term potentiation. I. Biol. Chem. 266: 24253-24256.

1992. Increased phosphorylation of a 17-kDa protein kinase $\mathrm{C}$ substrate (P17) in long-term potentiation. /. Neurochem. 58: 1576-1579.

1993. Mechanism of protein kinase $C$ activation during the induction and maintenance of long-term potentiation probed using a selective peptide substrate. Proc. Natl. Acad. Sci. 90: 8337-8341.

Klann, E., E.D. Roberson, and R.M. Mack. 1995. Modulation of long-term potentiation by reactive oxygen species. Soc. Neurosci. Abstr. 21: 1809.

Krug, M., B. Lössner, and T. Ott. 1984. Anisomycin block the late phase of long-term potentiation in the dentate gyrus of freely moving rats. Brain Res. Bull. 13: 39-42.

Leahy, J.C., Y. Luo, C.S. Kent, K.F. Meiri, and M.L. Vallano. 1993. Demonstration of presynaptic protein kinase $C$ activation following long-term potentiation in rat hippocampal slices. Neuroscience 52: 563-574.

Lisman, J. 1995. What does the nucleus know about memories? J. NIH Res. 7: 43-46.

Lisman, J.E. 1985. A mechanism for memory storage insensitive to molecular turnover: A bistable autophosphorylating kinase. Proc. Natl. Acad. Sci. 82: 3055-3057.

1994. The CaMKII hypothesis for storage of synaptic memory. Trends Neurosci. 17: 406-412.

Lisman, J.E. and M.A. Goldring. 1988. Feasibility of long-term storage of graded information by the $\mathrm{Ca}^{2+} /$ calmodulin-dependent protein kinase molecules of the postsynaptic density. Proc. Natl. Acad. Sci. 85: 5320-5324.

Lovinger, D.M., R.F. Akers, R.B. Nelson, C.A. Barnes, B.L. McNaughton, and A. Routtenberg. 1985. A selective increase in phosphorylation of protein $\mathrm{F} 1$, a protein kinase $\mathrm{C}$ substrate, directly related to three day growth of long term synaptic enhancement. Brain Res. 343: 137-143.

Lovinger, D.M., K.L. Wong, K. Murakami, and A. Routtenberg. 1987. Protein kinase $C$ inhibitors eliminate hippocampal long-term potentiation. Brain Res. 436: $177-183$.

Lynch, G., M. Browning, and W.F. Bennett. 1979. Biochemical and physiological studies of long-term synaptic plasticity. Fed. Proc. 38: 2117-2122.

Lynch, G., J. Larson, S. Kelso, G. Barrionuevo, and F. Schottler. 1983. Intracellular injections of EGTA block induction of hippocampal long-term potentiation. Nature 305: 719-721.

Lynch, M.A., M.P. Clements, K.L. Voss, C.R. Bramham, and
T.V.P. Bliss. 1991. Is arachidonic acid a retrograde messenger in long-term potentiation? Biochem. Soc. Trans. 19: $391-396$.

McGlade-McCulloh, E., H. Yamamoto, S.E. Tan, D.A. Brickey, and T.R. Soderling. 1993. Phosphorylation and regulation of glutamate receptors by calcium/calmodulin-dependent protein kinase II. Nature 362: 640-642.

Mackler, S.A., B.P. Brooks, and J.H. Eberwine. 1992. Stimulus-induced coordinate changes in mRNA abundance in single postsynaptic hippocampal CA1 neurons. Neuron 9: 539-548.

Malenka, R.C., D.V. Madison, and R.A. Nicoll. 1986. Potentiation of synaptic transmission in the hippocampus by phorbol esters. Nature 321: 175-177.

Malenka, R.C., G.S. Ayoub, and R.A. Nicoll. 1987. Phorbol esters enhance transmitter release in rat hippocampal slices. Brain Res. 403: 198-203.

Malenka, R.C., J.A. Kauer, R.S. Zucker, and R.A. Nicoll. 1988. Postsynaptic calcium is sufficient for potentiation of hippocampal synaptic transmission. Science 242: 81-84.

Malenka, R.C., J.A. Kauer, D.J. Perkel, M.D. Mauk, P.T. Kelly, R.A. Nicoll, and M.N. Waxham. 1989. An essential role for postsynaptic calmodulin and protein kinase activity in long-term potentiation. Nature 340: 554-557.

Malenka, R.C., B. Lancaster, and R.S. Zucker. 1992. Temporal limits on the rise in postsynaptic calcium required for the induction of long-term potentiation. Neuron 9: $121-128$

Malgaroli, A., R. Malinow, H. Schulman, and R.W. Tsien. 1992. Persistent signalling and changes in presynaptic function in long-term potentiation. Ciba Foundation Symposium 164: 176-191; discussion 192-196.

Malinow, R. 1991. Transmission between pairs of hippocampal slice neurons: Quantal levels, oscillations, and LTP. Science 252: 722-724.

Malinow, R., D.V. Madison, and R.W. Tsien. 1988. Persistent protein kinase activity underlying long-term potentiation. Nature 335: 820-824.

Malinow, R., H. Schulman, and R.W. Tsien. 1989. Inhibition of postsynaptic PKC or CaMKII blocks induction but not expression of LTP. Science 245: 862-866.

Manabe, T. and R.A. Nicoll. 1994. Long-term potentiation: Evidence against an increase in transmitter release probability in the CA1 region of the hippocampus. Science 265: 1888-1892.

Matthies, H. and K.G. Reymann. 1993. Protein kinase A inhibitors prevent the maintenance of hippocampal long-term potentiation. NeuroReport 4: 712-714.

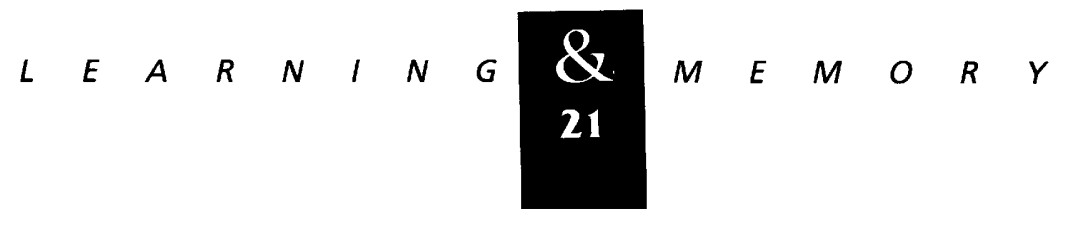


Matthies, H., Jr., T. Behnisch, H. Kase, $H$. Matthies, and K.G. Reymann. 1991. Differential effects of protein kinase inhibitors on pre-established long-term potentiation in rat hippocampal neurons in vitro. Neurosci. Lett. 121: 259-262.

Mayford, M., J. Wang, E.R. Kandel, and T.J. O'Dell. 1995. CaMKII regulates the frequency-response function of hippocampal synapses for the production of both LTD and LTP. Cell 81: 891-904.

Meffert, M.K., J.E. Haley, E.M. Schuman, H. Schulman, and D.V. Madison. 1994. Inhibition of hippocampal heme oxygenase, nitric oxide synthase, and long-term potentiation by metalloporphyrins. Neuron 13: 1225-1233.

Miyakawa, H., W.N. Ross, D. Jaffe, J.C. Callaway, N. Lasser-Ross, J.E. Lisman, and D. Johnston. 1992. Synaptically activated increases in $\mathrm{Ca}^{2+}$ concentration in hippocampal CA1 pyramidal cells are primarily due to voltage-gated $\mathrm{Ca}^{2+}$ channels. Neuron 9: 1163-1173.

Mochly-Rosen, D. and D.E. Koshland, Jr. 1987. Domain structure and phosphorylation of protein kinase C. J. Biol. Chem. 262: 2291-2297.

Morris, B.J., K.J. Feasey, G. ten Bruggencate, A. Herz, and V. Höllt. 1988. Electrical stimulation in vivo increases the expression of proenkephalin mRNA and decreases the expression of prodynorphin mRNA in rat hippocampal granule cells. Proc. Natl. Acad. Sci. 85: 3226-3230.

Moss, S.J., C.D. Blackstone, and R.L. Huganir. 1993. Phosphorylation of recombinant non-NMDA glutamate receptors on serine and tyrosine residues. Neurochem. Res. 18: $105-110$.

Muller, D., J. Turnbull, M. Baudry, and G. Lynch. 1988. Phorbol ester-induced synaptic facilitation is different than long-term potentiation. Proc. Natl. Acad. Sci.

85: 6997-7000.

Muller, D., P.A. Buchs, Y. Dunant, and G. Lynch. 1990. Protein kinase $C$ activity is not responsible for the expression of long-term potentiation in hippocampus. Proc. Natl. Acad. Sci. 87: 4073-4077.

Muller, D., P. Bittar, and H. Boddeke. 1992. Induction of stable long-term potentiation in the presence of the protein kinase-C antagonist staurosporine. Neurosci. Lett. 135: 18-22.

Nelson, R.B., D.J. Linden, C. Hyman, K.H. Pfenninger, and A. Routtenberg. 1989. The two major phosphoproteins in growth cones are probably identical to two protein kinase $C$ substrates correlated with persistence of long-term potentiation. /. Neurosci. 9: 381-389.

Nguyen, P.V. and E.R. Kandel. 1996. A macromolecular synthesis-dependent late phase of long-term potentiation required CAMP in the medial perforant pathway of rat hippocampal slices. I. Neurosci. 16: 3189-3198.

Nguyen, P.V., T. Abel, and E.R. Kandel. 1994. Requirement for a critical period of transcription for a late phase of LTP. Science 265: 1104-1107.

Nishizuka, Y. 1992. Intracellular signaling by hydrolysis of phospholipids and activation of protein kinase C. Science 258: $607-614$.

Obenaus, A., I. Mody, and K.G. Baimbridge. 1989. Dantrolene- $\mathrm{Na}$ (Dantrium) blocks induction of long-term potentiation in hippocampal slices. Neurosci. Lett. 98: $172-178$.

Ocorr, K.A. and H. Schulman. 1991. Activation of multifunctional $\mathrm{Ca}^{2+} /$ calmodulin-dependent kinase in intact hippocampal slices. Neuron 6: 907-914.

O'Dell, T.J., R.D. Hawkins, E.R. Kandel, and O. Arancio. 1991a. Tests of the roles of two diffusible substances in long-term potentiation: Evidence for nitric oxide as a possible early retrograde messenger. Proc. Natl. Acad. Sci. 88: $11285-11289$.

O'Dell, T.J., E.R. Kandel, and S.G.N. Grant. 1991b. Long-term potentiation in the hippocampus is blocked by tyrosine kinase inhibitors. Nature 353: 558-560.

O'Dell, T.J., P.L. Huang, T.M. Dawson, J.L. Dinerman, S.H. Snyder, E.R. Kandel, and M.C. Fishman. 1994. Endothelial NOS and the blockade of LTP by NOS inhibitors in mice lacking neuronal NOS. Science 265: 542-546.

Pang, D.T., J.K.T. Wang, F. Valtorta, F. Benfenati, and P. Greengard. 1988. Protein tyrosine phosphorylation in synaptic vesicles. Proc. Natl. Acad. Sci. 85: 762-766.

Perkel, D.J., J.J. Petrozzino, R.A. Nicoll, and J.A. Connor. 1993. The role of $\mathrm{Ca}^{2+}$ entry via synaptically activated NMDA receptors in the induction of long-term potentiation. Neuron 11: 817-823.

Pettit, D.L., S. Perlman, and R. Malinow. 1994. Potentiated transmission and prevention of further LTP by increased CaMKII activity in postsynaptic hippocampal slice neurons. Science 266: 1881-1885.

Powell, C.M., D. Johnston, and J.D. Sweatt. 1994. Autonomously active protein kinase $\mathrm{C}$ in the maintenance phase of $\mathrm{N}$-methyl-D-aspartate receptor-independent long term potentiation. J. Biol. Chem. 269: 27958-27963.

Ramakers, G.M., P.N. de Graan, I.J. Urban, D. Kraay, T. Tang, P. Pasinelli, A.B. Oestreicher, and W.H. Gispen. 1995. Temporal differences in the phosphorylation state of pre- and postsynaptic protein kinase $C$ substrates B-50/GAP-43 and neurogranin during long-term potentiation. J. Biol. Chem. 270: 13892-13898.

Regehr, W.G. and D.W. Tank. 1992. Calcium concentration dynamics produced by synaptic activation of CA1 hippocampal pyramidal cells. J. Neurosci. 12: 4202-4223.

Represa, A., J.C. Deloume, M. Sensenbrenner, Y. Ben-Ari, and J. Baudier. 1990. Neurogranin: Immuno-cytochemical

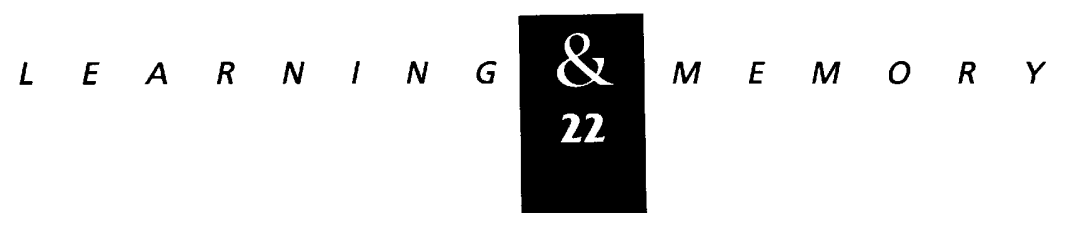


localization of a brain-specific protein kinase C substrate. /. Neurosci. 10: 3782-3792.

Reymann, K.G., R. Brodemann, H. Kase, and H. Matthies. 1988a. Inhibitors of calmodulin and protein kinase $C$ block different phases of hippocampal long-term potentiation. Brain Res. 461: 388-392.

Reymann, K.G., K. Schulzeck, H. Kase, and H. Matthies. 1988b. Phorbol ester induced hippocampal long-term potentiation is counteracted by inhibitors of protein kinase $C$. Exp. Brain Res. 71: 227-230.

Reymann, K.G., S.N. Davies, H. Matthies, H. Kase, and G.L. Collingridge. 1990. Activation of a K-252b-sensitive protein kinase is necessary for a post-synaptic phase of long-term potentiation in area CA1 of rat hippocampus. Eur. J. Neurosci. 2: 481-486.

Roberson, E.D. and J.D. Sweatt. 1993. Cyclic AMP-dependent protein kinase is activated during the induction of long-term potentiation. Soc. Neurosci. Abstr. 19: 1708 .

Roberson, E.D., and J.D. Sweatt. 1996. Transient activation of cyclic AMP-dependent protein kinase during hippocampal long-term potentiation. J. Biol. Chem. (in press).

Ruegg, U.T. and G.M. Burgess. 1989. Staurosporine, k-252 and $\mathrm{UCN}-01$ : Potent but nonspecific inhibitors of protein kinases. Trends Pharmacol. Sci. 10: 218-220.

Sacktor, T.C., P. Osten, H. Valsamis, X. Jiang, M.U. Naik, and E. Sublette. 1993. Persistent activation of the zeta isoform of protein kinase $C$ in the maintenance of long-term potentiation. Proc. Natl. Acad. Sci. 90: 8342-8346.

Schuman, E.M. and D.V. Madison. 1991. A requirement for the intercellular messenger nitric oxide in long-term potentiation. Science 254: 1503-1506.

1994. Locally distributed synaptic potentiation in the hippocampus. Science 263: 532-536.

Schuman, E.M., M.K. Meffert, H. Schulman, and D.V. Madison. 1994. An ADP-ribosyltransferase as a potential target for nitric oxide action in hippocampal long-term potentiation. Proc. Natl. Acad. Sci. 91: 11958-11962.

Schwartz, J.H. 1993. Cognitive kinases. Proc. Natl. Acad. Sci. 90: 8310-8313.

Silva, A.J., C.F. Stevens, S. Tonegawa, and Y. Wang. 1992. Deficient hippocampal long-term potentiation in alpha-calcium-calmodulin kinase II mutant mice. Science 257: 201-206.

Stevens, C.F. and Y. Wang. 1993. Reversal of long-term potentiation by inhibitors of heme oxygenase. Nature 364: $147-149$

1994. Changes in reliability of synaptic function as a mechanism for plasticity. Nature 371: 652-653.
Swandulla, D., M. Hans, K. Zipser, and G.J. Augustine. 1991. Role of residual calcium in synaptic depression and posttetanic potentiation: Fast and slow calcium signaling in nerve terminals. Neuron 7: 915-926.

Taube, J.S. and P.A. Schwartzkroin. 1986. Ineffectiveness of organic calcium channel blockers in antagonizing long-term potentiation. Brain Res. 379: 275-285.

Umemori, H., S. Sato, T. Yagi, S. Aizawa, and T. Yamamoto. 1994. Initial events of myelination involve fyn tyrosine kinase signaling. Nature 367: 572-576.

van Hooff, C.O., P.N. de Graan, ]. Boonstra, A.B. Oestreicher, M.H. Schmidt-Michels, and W.H. Gispen. 1986. Nerve growth factor enhances the level of the protein kinase C substrate B-50 in pheochromocytoma $\mathrm{PC1} 2$ cells. Biochem. Biophys. Res. Comm. 139: 644-651.

van Lookeren Campagne, M., A.B. Oestreicher, P.M. van Bergen en Henegowen, and W.H. Gispen. 1989. Ultrastructural immunocytochemical localization of B-50/GAP43, a protein kinase C substrate, in isolated presynaptic nerve terminals and neuronal growth cones. /. Neurocytol. 18: 479-489.

Wang, J.H. and D.P. Feng. 1992. Postsynaptic protein kinase-C essential to induction and maintenance of long-term potentiation in the hippocampal CA1 region. Proc. Natl. Acad. Sci. 89: 2576-2580.

Wang, J.H. and P.T. Kelly. 1995. Postsynaptic injection of $\mathrm{Ca}^{2+} / \mathrm{CaM}$ induces synaptic potentiation requiring CaMKII and PKC activity. Neuron 15: 443-452.

Watson, J.B., K.K. Battenberg, F.E. Wong, F.E. Bloom, and J.G. Sutcliffe. 1990. Subtractive cDNA cloning of RC3, a rodent cortex-enriched mRNA encoding a novel 78 residue protein. I. Neurosci. 26: 397-408.

Williams, J.H. and T.V.P. Bliss. 1989. An in vitro study of the effect of lipoxygenase and cyclo-oxygenase inhibitors of arachidonic acid on the induction and maintenance of long-term potentiation in the hippocampus. Neurosci. Lett. 107: 301-306.

Williams, J.H., M.L. Errington, M.A. Lynch, and T.V.P. Bliss. 1989. Arachidonic acid induces a long-term activity-dependent enhancement of synaptic transmission in the hippocampus. Nature 341: 739-742.

Williams, J.H., Y.-G. Li, A. Nayak, M.L. Errington, K.P. Murphy, and T.V.P. Bliss. 1993. The suppression of long-term potentiation in rat hippocampus by inhibitors of nitric oxide synthase is temperature and age dependent. Neuron 11: 877-884.

Xia, Z., C.D. Refsdal, K.M. Merchant, D.M. Dorsa, and D.R. Storm. 1991. Distribution of mRNA for the calmodulin-sensitive adenylate cyclase in rat brain: Expression in areas associated with learning and memory. Neuron 6: 431-443. 
Roberson et al.

Yamamoto, K.K., G.A. Gonzalez, W.H. Biggs, and M.R. Montminy. 1988. Phosphorylation-induced binding and transcriptional efficacy of nuclear factor CREB. Nature 334: 494-498.

Zhuo, M., S.A. Small, E.R. Kandel, and R.D. Hawkins. 1993. Nitric oxide and carbon monoxide produce activity-dependent long-term synaptic enhancement in hippocampus. Science 260: 1946-1950.

Zhuo, M., Y. Hu, C. Schultz, E.R. Kandel, and R.D. Hawkins. 1994. Role of guanylyl cyclase and cGMP-dependent protein kinase in long-term potentiation. Nature 368: 635-639. 


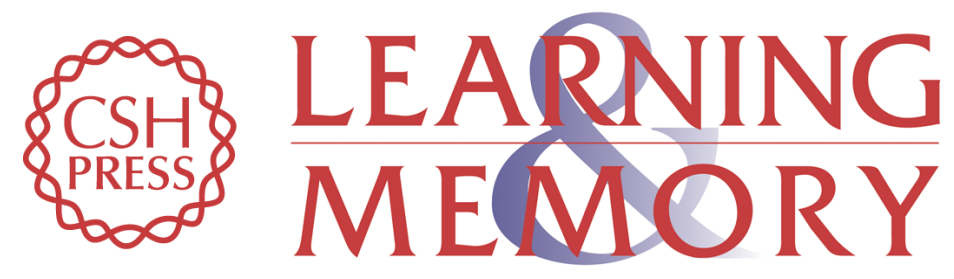

\title{
A biochemist's view of long-term potentiation.
}

\author{
E D Roberson, J D English and J D Sweatt
}

Learn. Mem. 1996, 3:

Access the most recent version at doi:10.1101//m.3.1.1

References This article cites 160 articles, 59 of which can be accessed free at: http://learnmem.cshlp.org/content/3/1/1.full.html\#ref-list-1

License

Email Alerting Receive free email alerts when new articles cite this article - sign up in the box at the Service top right corner of the article or click here. 